\title{
Increasing Hormonal Control of Skeletal Development: An Evolutionary Trend in Amphibians
}

\author{
Anna B. Vassilieva* and Sergei V. Smirnov \\ A.N. Severtsov Institute of Ecology and Evolution, Russian Academy of Sciences, Moscow, Russia
}

The biphasic life history of amphibians includes metamorphosis, a complex developmental event that involves drastic changes in the morphology, physiology and biochemistry accompanying the transition from the larval to adult stage of development. Thyroid hormones (THs) are widely known to orchestrate this remodeling and, in particular, to mediate the development of the bony skeleton, which is a model system in evolutionary morphological studies of amphibians. Detailed experimental studies of the role of THs in the craniogenesis of diverse urodelan amphibians revealed that (i) these hormones affect both the timing and sequence of bone formation, (ii) $\mathrm{TH}$ involvement increases in parallel with the increase in divergence between larval and adult skull morphology, and (iii) among urodelans, TH-involvement in skull development changes from a minimum in basal salamanders (Hynobiidae) to the most pronounced in derived ones (Salamandridae and Plethodontidae). Given the increasing regulatory function of

OPEN ACCESS

Edited by:

Sarah Kelly McMenamin, Boston College, United States

Reviewed by:

Pedro Martinez,

University of Barcelona, Spain Daniel Buchholz,

University of Cincinnati, United States

${ }^{*}$ Correspondence:

Anna B. Vassilieva vassil.anna@gmail.com

Specialty section:

This article was submitted to Evolutionary Developmental Biology,

a section of the journal

Frontiers in Ecology and Evolution

Received: 30 June 2021

Accepted: 05 October 2021 Published: 04 November 2021

Citation:

Vassilieva $A B$ and Smirnov $S V$ (2021) Increasing Hormonal Control of Skeletal Development: An Evolutionary Trend in Amphibians. Front. Ecol. Evol. 9:733947. doi: 10.3389/fevo.2021.733947
THs in urodelan evolution, we hypothesized a stronger involvement of THs in the control of skeletogenesis in anurans with their most complex and dramatic metamorphosis among all amphibians. Our experimental study of skeletal development in the hypoand hyperthyroid yellow-bellied toad (Bombina variegata: Bombinatoridae) supports the greater involvement of $\mathrm{THs}$ in the mediation of all stages of anuran cranial and postcranial bones formation. Similar to urodelans, $B$. variegata displays enhancing $\mathrm{TH}$ involvement in the development of cranial bones that arise during larval ontogeny: while the hormonal impact on early larval ossifications is minimal, the skull bones forming during metamorphosis are strictly $\mathrm{TH}$-inducible. However, in contrast to urodelans, all cranial bones, including the earliest to form, are $\mathrm{TH}$-dependent in $B$. variegata; moreover, the development of all elements of the axial and limb skeleton is affected by THs. The more accentuated hormonal control of skeletogenesis in $B$. variegata demonstrates the advanced regulatory and inductive function of THs in the orchestration of anuran metamorphosis. Based on these findings, we discuss (i) changes in THs function in amphibian evolution and (ii) the role of THs in the evolution of life histories in amphibians.

Keywords: Bombina, heterochronies, life history, metamorphosis, skeletogenesis, thyroid hormones

\section{INTRODUCTION}

The amphibian life cycle consisting of water-dwelling larvae and terrestrial adults is unique among vertebrate animals. The main event in amphibian development is metamorphosis, a cascade of transformations at the molecular, biochemical, physiological, and morphological levels (for reviews, see, e.g., Fritzsch, 1990; Furlow and Neff, 2006; Brown and Cai, 2007). The extent of 
this transformation differs in the different amphibian lineages. Caecilians, a very specialized group of fossorial or aquatic amphibians, display only moderate morphological reorganization limited mainly to the loss of gills and rebuilding of the palatal region of the skull and hyobranchium (Wake, 1989; Reiss, 1996). At metamorphosis, urodelans retain the overall larval body plan, although undergo profound changes in the external and internal morphology. In them, resorption of the external gills and caudal fins is accompanied by changes in the skull structure: larval provisory bones disappear, and adult bones appear (Rose, 2003). In anurans, metamorphic transformation is extremely profound and results in the remodeling of the body plan: fish-like aquatic larvae transform into tailless terrestrial animals adapted to jumping. At metamorphosis, the larval cartilaginous jaw apparatus is replaced by an adult bony apparatus, suspensorium undergoes rebuilding, and the jaw joint shifts posteriorly (Roček, 2003).

Based on these differences in the degree of metamorphic transformations, the evolution of amphibian metamorphosis was hypothesized to be a transition from slow, gradual, and ill-defined metamorphosis in the recent amphibians' ancestors, temnospondyls, to explosive, necrobiotic anuran metamorphosis with complete disappearance of some larval elements and/or complete remodeling of the others (Reiss, 2002; Schoch, 2009).

Thyroid hormones (THs) are well known to play a key role in the mediation of amphibian metamorphosis; mechanisms and functions of thyroid hormone signaling are widely described in numerous publications (for reviews, see, e.g., Galton, 1992; Tata, 1999; Fort et al., 2007; Grimaldi et al., 2013). The development and functional dynamics of the thyroid gland have been studied in a number of anuran and urodelan species; typically, in biphasic amphibians completing metamorphosis, the level of THs is low in early larval stages, rises closer to metamorphosis, reaches its peak at metamorphic climax when most transformation occurs and then lowers after full metamorphic transformation (for anurans, see, e.g., Regards et al., 1978; Weil, 1986; Weber et al., 1994; for urodelans, Eagleson and McKeown, 1978; LarrasRegard et al., 1981; Alberch et al., 1986). The role of THs in the evolutionary diversification of amphibian developmental patterns (metamorphosis, neoteny, and direct development) is rather well documented (Laudet, 2011). However, while our knowledge on the function of the thyroid axis at the level of thyroid receptors, gene expression and interplay with different endocrine factors, among others, is rather extensive, the role of THs in "the last link," morphogenesis, remains rather poorly studied.

TH-mediation in the development of the amphibian skeleton is also relatively poorly studied. This is extremely surprising since the skeleton is a traditional model system for evodevo investigation. Thus, in amphibians, most studies on different heterochronies (now considered one of the main mechanisms of evolutionary changes) are based on data from skeletal morphology (e.g., Reilly et al., 1997; Schlosser, 2001; Sheil et al., 2014).

Although skeletal changes accompanying amphibian metamorphosis are proposed to be TH-mediated, concrete studies aimed at investigating this phenomenon are rather rare. Apodans remain unstudied in this respect. Compared with them, urodelans (salamanders) seem to be rather well studied. Thus, dysfunction of the thyroid axis was revealed to account for the absence of several bones in neotenic salamanders retaining larval cranial morphology as an adult morphology (Larsen, 1968; Rosenkilde and Ussing, 1996; Rose, 2003). Thyroid axis involvement in the cranial development of plethodontids and salamandrids was estimated in a series of experiments with exogenous $\mathrm{TH}$ and goitrogen treatment of larvae developing in a regime of high and low $\mathrm{TH}$ levels or hypophysectomized larvae (Rose, 1995a,b, 1996; Clemen and Greven, 2018; Ajduković et al., 2021).

In our laboratory, the role of THs in the skeletal development of salamanders has been studied during the last two decades. For this aim, changes in skeletal morphology (timing and sequence of bone appearance) were compared in larvae reared under different TH regimes: normal (in control larvae), low (under treatment with a goitrogen, thiourea, causing $\mathrm{TH}$-deficiency), and high (under treatment with exogenous $\mathrm{TH}$, triidothyronine at different concentrations). This standard protocol of the experiment was applied to both the basal and derived salamanders: the Siberian newt Salamandrella keyserlingii (Hynobiidae), axolotl Ambystoma mexicanum (Ambystomatidae), the Ribbed newt Pleurodeles walt and Smooth newt Lissotriton vulgaris (Salamandridae) (Smirnov and Vassilieva, 2003, 2005; Smirnov et al., 2011, 2020). Accumulated evidence suggests that urodelan evolution is accompanied by an increasing TH-impact on cranial metamorphic remodeling (Smirnov, 2006).

Concerning anurans, similar experimental studies are relatively scarce. Although the pattern of their metamorphosis proposes an important role of $\mathrm{THs}$ in the orchestration of numerous complex transformations occurring in synchrony, our knowledge on the role of THs in anuran skeletal development remains fragmentary. Thus, TH-treatment was shown to accelerate the development of several cranial bones in Lithobates pipiens (Ranidae) and in the Oriental fire-bellied toad Bombina orientalis (Bombinatoridae) (Kemp and Hoyt, 1965a,b; Hanken and Hall, 1988b). Additionally, treatment with goitrogens inhibiting thyroid function or exogenous thyroid hormones resulted in changes in the rate of metamorphic transformations in the chondrocranium of B. orientalis, Clawed frog Xenopus laevis (Pipidae), and direct-developing frog Puerto Rican Coqui Eleutherodactylus coqui (Eleutherodactylidae) (Hanken and Summers, 1988; Callery and Elinson, 2000; Rose and Cahill, 2019). Our preliminary experiments revealed that in $X$. laevis and the Common frog Rana temporaria (Ranidae), development of most cranial bones is dependent upon the TH-level (Vassilieva and Smirnov, 2007; Smirnov and Vassilieva, 2014). Recent experiments involving parallel TH and goitrogen treatment of several non-model leptodactylid frogs revealed, correspondingly, accelerating and inhibiting effects on some cranial bones (Fabrezi et al., 2019). Moreover, THs seem to influence the development of the postcranial skeleton since ossification of limbs and axial skeleton was shown to be TH-mediated (Kemp and Hoyt, 1969; Fabrezi et al., 2019; Senevirathne et al., 2020). 
Although this evidence does not provide a complete picture of the role of THs in skeletal development, it proposes that THs are involved in the mediation of metamorphic transformation to a greater extent in anurans than in urodelans. To test this hypothesis, we experimentally studied the role of THs in the skeletal development of the Yellow-bellied toad Bombina variegata (Bombinatoridae). To make the results comparable, we used the same experimental protocol both for this toad and salamanders previously studied by us.

The reason we chose this toad to study is that (i) the morphology and skeletal development of Bombina were previously described in detail (e.g., Maglia and Púgener, 1998; Lukas and Olsson, 2020; Roček et al., 2021), (ii) B. orientalis was used in pioneering experimental studies on the TH-mediation of cranial development in anurans (Hanken and Hall, 1988b; Hanken and Summers, 1988), and (iii) B. variegata belongs to the basal anuran family.

Based on our observations and published data on THinvolvement in the skeletal development of anurans and urodelans, we discuss (i) the evolution of TH-function in the amphibian phylogeny and (ii) the putative role of THs in the evolution of amphibian life histories.

\section{MATERIALS AND METHODS}

The ontogenetic series of Bombina variegata larvae were obtained and reared under laboratory conditions in two sets of experiments using different concentrations of TH. Egg clutches for Experiment I performed in 2007 derived from the breeding group of five males and five females of $B$. variegata obtained from trade. Breeding was stimulated by injections of the adults with chorionic gonadotropin. Clutches for Experiment II performed in 2019 derived from spontaneous spawning of a B. variegata breeding group (four males and three females) housed in the batrachological section in the Moscow Zoo (Moscow, Russia). Larvae were reared in aquaria with different experimental media: (i) clear tap water (controls); (ii) alkaline solutions of 3, $3^{1}, 5$-triiodothyronine ( $\mathrm{T}_{3}$; Sigma Chemical Co., Germany) at concentrations of $2 \times 10^{-8} \mathrm{M}, 2 \times 10^{-9} \mathrm{M}$, and $2 \times 10^{-10}$ $\mathrm{M}$; and (iii) $0.02 \%$ and $0.04 \%$ solutions of goitrogen thiourea (TU; Solins, Russia). Previously, similar concentrations of $\mathrm{T}_{3}$ and TU were used in experimental studies of the TH-effect on skeletogenesis in urodelan (Smirnov and Vassilieva, 2003, 2005; Smirnov et al., 2011, 2020) and anuran amphibians (Vassilieva and Smirnov, 2007; Smirnov and Vassilieva, 2014). In Experiment $\mathrm{I}$, treatment of the different groups of larvae with $\mathrm{T}_{3}$ and $\mathrm{TU}$ started at 6 and 7 days posthatching (dph), respectively, soon after the beginning of exogenous feeding. In Experiment II, $\mathrm{T}_{3}$ treatment of tadpoles started at six dph and at $15 \mathrm{dph}$. In total, 206 and 106 specimens were used in Experiments I and II, respectively; for details, see Table 1.

The animals from every experimental and control group were kept at the same density (120 L aquaria, each initially containing approximately 30 larvae) and temperature $18-22^{\circ} \mathrm{C}$ under a natural light regime. One-half of the rearing medium was replaced every day. The larvae were fed ad libitum with chopped and scalded common nettle leaves (Urtica dioica). The larvae were reared until the end of metamorphosis (normal and TH-induced) or until the end of the experiment for the TUtreated individuals (over 120 days for several specimens). The larvae were sampled at regular intervals (every day or every 2nd day for controls and TU-treated larvae, every day for THtreated larvae, and every week for TU-treated larvae older than 2 months) and fixed in $10 \%$ neutral buffered formalin. The larvae were staged following Gosner (1960), and the snout-vent length (SVL) was measured with an electronic caliper to the nearest $0.1 \mathrm{~mm}$. One specimen, a mature male (SVL $41.2 \mathrm{~mm}$ ) among breeding group (Experiment I), was used to examine adult skeletal morphology. All specimens were prepared as skeletal whole mounts. They were stained with Alizarin red to detect calcium deposits and cleared in $\mathrm{KOH}$; additionally, three to five specimens from the control and experimental groups were stained with Alcian blue for cartilage following the protocol described by Wassersug (1976). The whole mounts were analyzed for skeleton development under a stereomicroscope (Olympus SZX7) with digital photo attachment. The timing of ossification was recorded as the first observable sign of Alizarin red staining. The terminology used for the bones and cartilages generally follows Maglia and Púgener (1998). For actual taxonomy, we followed an updated database by Frost (2021).

All procedures were carried out in accordance with the Severtsov Institute's Animal Ethics Committee.

\section{RESULTS}

\section{Larval Development Under Different Hormonal Regimes}

Larvae hatch after 6 days of embryonic development and start exogenous feeding on 4-5 dph. Control tadpoles start to leave the water at 30-31 dph, and the first of them complete metamorphosis at 33-34 dph.

At $2 \times 10^{-10} \mathrm{M} \mathrm{T}_{3}$, developing tadpoles do not differ externally from the norm, and the rate of metamorphosis is only slightly accelerated.

At $2 \times 10^{-9} \mathrm{M} \mathrm{T}_{3}$, larval development is strongly accelerated, resulting in precocious metamorphosis: the first metamorphs leave the water and attain St. 46 approximately 10 days before the norm, being markedly smaller in size (see Table 1). The external metamorphic changes of the head, tail, and skin structures anticipate Gosner's staging based on the development of the limbs: by St. 38, the tail fins start to reduce, the cloacal tail piece is absent, the keratodonts and mouth sheaths are lost, the snout shortens and the eyes become enlarged and more salient.

At $2 \times 10^{-8} \mathrm{M} \mathrm{T}_{3}$, metamorphic changes of the skin structures (reduction of tail fins, cloacal tail piece, and opercular fold) and mouthparts (loss of keratodonts and mouth sheaths) as well as tail resorption, head transformation (shortening of the snout, eyes and nostrils bulging), and larval gut remodeling, are greatly accelerated. The discrepancies between the staging based on limb development (differentiation of the digits) and head transformation attain several stages: e.g., after 14 days of treatment, at $20 \mathrm{dph}$, tadpoles with hindlimb differentiation 
TABLE 1 | Specimens of Bombina variegata examined in the experimental study.

\begin{tabular}{|c|c|c|c|c|c|}
\hline Experimental group & $\begin{array}{c}\text { Beginning of } \\
\text { stimulation (dph) }\end{array}$ & Experiment duration (dph) & $\begin{array}{c}\text { Attained } \\
\text { developmental stage }\end{array}$ & Number of specimens & SVL range $(\mathrm{mm})$ \\
\hline \multicolumn{6}{|l|}{ Experiment I (2007) } \\
\hline Norm I & - & 37 & 46 & 63 & $6.0-19.5$ \\
\hline $\mathrm{T}_{3} 2 \times 10^{-10} \mathrm{M}$ & 6 & 34 & 46 & 23 & $10.0-18.0$ \\
\hline $\mathrm{T}_{3} 2 \times 10^{-9} \mathrm{M}$ & 6 & 27 & 46 & 44 & $8.5-13.5$ \\
\hline Thiourea $0.02 \%$ & 7 & 75 & $43-44$ & 34 & $9.0-19.0$ \\
\hline Thiourea $0.04 \%$ & 7 & 123 & $38-39$ & 42 & $9.0-22.0$ \\
\hline \multicolumn{6}{|l|}{ Experiment II (2019) } \\
\hline Norm II & - & 34 & 46 & 53 & $8.0-18.5$ \\
\hline $\mathrm{T}_{3} 2 \times 10^{-8} \mathrm{M}$ early & 6 & 20 & 35 & 24 & $5.0-6.6$ \\
\hline $\mathrm{T}_{3} 2 \times 10^{-8} \mathrm{M}$ late & 15 & 22 & $37 / 42$ & 29 & $5.3-11.5$ \\
\hline
\end{tabular}

dph, days post hatching; SVL, snout-vent length.

corresponding to Stage 36 or 37 display the erupted forelimbs, oral disk loss and mouth width corresponding to Stage 42 . These tadpoles stop feeding and do not develop further; at this stage, the experiment is terminated.

In goitrogen-treated (TU 0.02\%) larvae, development is markedly retarded. The most advanced individuals reach St. 4344 and begin to leave the water at $69-70 \mathrm{dph}$, but none of them complete metamorphosis during the experiment. Several individuals arrest development at St. 38. No specific changes in the external morphological features are observed in them compared with the norm.

Tadpoles treated with $0.04 \%$ TU stop developing at the late midlarval stages (38-39), and none of them begin any metamorphic transformations during the experiment. Many individuals display lateral curvatures of the posterior part of the vertebral column or tail.

\section{Bony Skull Development Under Different Hormonal Regimes Control Groups}

The adult osteology and normal skeletal development of $B$. variegata revealed in our study are mostly consistent with those of B. orientalis, described in detail by Hanken and Hall (1984, 1988a) and Maglia and Púgener (1998). Adult morphology differs mainly in the absence of the interfrontal bone in the skull roof in $B$. variegata and the absence of the fusions of vertebrae I + II and VII + VIII, found in B. orientalis (Maglia and Púgener, 1998) but not observed in our adult specimen.

The typical sequence and staging of skeletal ossification in normally developing larvae are summarized in Table 2. The first signs of ossifications appear at the early St. 36, in approximately two-week-old, fast growing tadpoles. Cranial ossification usually starts with the dermal bone parasphenoid underlying the neurocranium. This is followed by the paired dermal frontoparietal in the skull roof. This midlarval skull development is completed by the formation of the first endochondral bone, the paired exoccipital, which appears behind the well chondrified otic capsule lateral to the foramen magnum.
The premetamorphic phase of development starting at St. 39 is characterized by the appearance of several paired dermal bones in the rostral part of the skull. The premaxilla arises on its frontal surface. The facial process of this bone is the first to form; it persists as a single ossified portion of the premaxilla until the onset of metamorphosis (Figure 1). The septomaxilla forms as a small semicircular ossicle close to the narial opening. The next bones to appear, the vomer on the skull base anterior to the parasphenoid and the nasal on the dorsal surface of the nasal capsules, form almost synchronously.

The metamorphic period beginning with the appearance of the forelimbs at St. 42 is characterized by a drastic head transformation and the formation of several dermal bones. The squamosal on the lateral side of the palatoquadrate and the angulosplenial on the ventral surface of Meckel's cartilage arise simultaneously. At the same time, the dental process of the premaxilla forms ventral to the facial process and then fuses to the latter, forming an entire bone. The maxilla appears lateral to the premaxilla in the upper jaw and grows toward the corners of the laterally expanding mouth opening. The dentary arises in the lower jaw medial and rostral to the angulosplenial. The quadratojugal forms on the lateral surface of the palatoquadrate near the jaw joint; next, the pterygoid appears on the inner surface of the same cartilage in the oral cavity roof. Finally, the endochondral prootic bone appears in the anterior part of the otic capsule; by metamorphosis completion, the otic capsule becomes partially ossified due to the expanding growth of the exoccipital and prootic in its posterior and anterior parts, respectively. Toward the end of metamorphosis, at St. 46, the only hyobranchial ossification, the endochondral os thyroideum appears as paired thin rodlike anlagen, but in our series, it is present in only one of five postmetamorphic animals.

In the samples studied, the endochondral mentomeckelian and sphenethmoid fail to appear in the young metamorphs; their formation is shifted to postmetamorphic development.

The sequence of skeletal development is almost invariable: in both control groups, only in a single specimen does the 
TABLE 2 | Sequence of skeletal ossification in Bombina variegata listed as the earliest bones appearance (normal development).

\begin{tabular}{|c|c|c|c|c|}
\hline Stage & Skull & Axial skeleton & Hind limb and pelvic girdle & Forelimb and pectoral girdle \\
\hline 36 & $\begin{array}{l}\text { Parasphenoid } \\
\text { Frontoparietal }\end{array}$ & First neural arches & $\begin{array}{l}\text { Femur } \\
\text { Fibula } \\
\text { Tibia } \\
\text { Tarsals }\end{array}$ & $\begin{array}{l}\text { Humerus } \\
\text { Ulna } \\
\text { Radius }\end{array}$ \\
\hline 37 & Exoccipital & $\begin{array}{l}\text { Neural arches I-VIII } \\
\text { Neural arch IX } \\
\text { First centra }\end{array}$ & $\begin{array}{l}\text { llium } \\
\text { First metatarsals }\end{array}$ & $\begin{array}{l}\text { Cleithrum } \\
\text { First metacarpals } \\
\text { [Coracoid, clavicle] } \\
\text { Scapula }\end{array}$ \\
\hline 38 & & $\begin{array}{l}\text { Neural arch X } \\
\text { Hypochord }\end{array}$ & First phalanges & First phalanges \\
\hline 39 & Premaxilla & Neural arch XI & & \\
\hline 40 & Septomaxilla & Ribs & All phalanges & All phalanges \\
\hline 41 & [Vomer, nasal] & & & \\
\hline 42 & [Squamosal, angulosplenial] & & Ischium & \\
\hline 43 & $\begin{array}{l}\text { Maxilla } \\
\text { Dentary }\end{array}$ & & & \\
\hline 44 & Quadratojugal & & & \\
\hline 45 & $\begin{array}{l}\text { Pterygoid } \\
\text { Prootic }\end{array}$ & & & \\
\hline 46 & Os thyroideum & Urostyle formed & & \\
\hline
\end{tabular}

Elements in [brackets] appear simultaneously or the sequence of their appearance is not resolved.

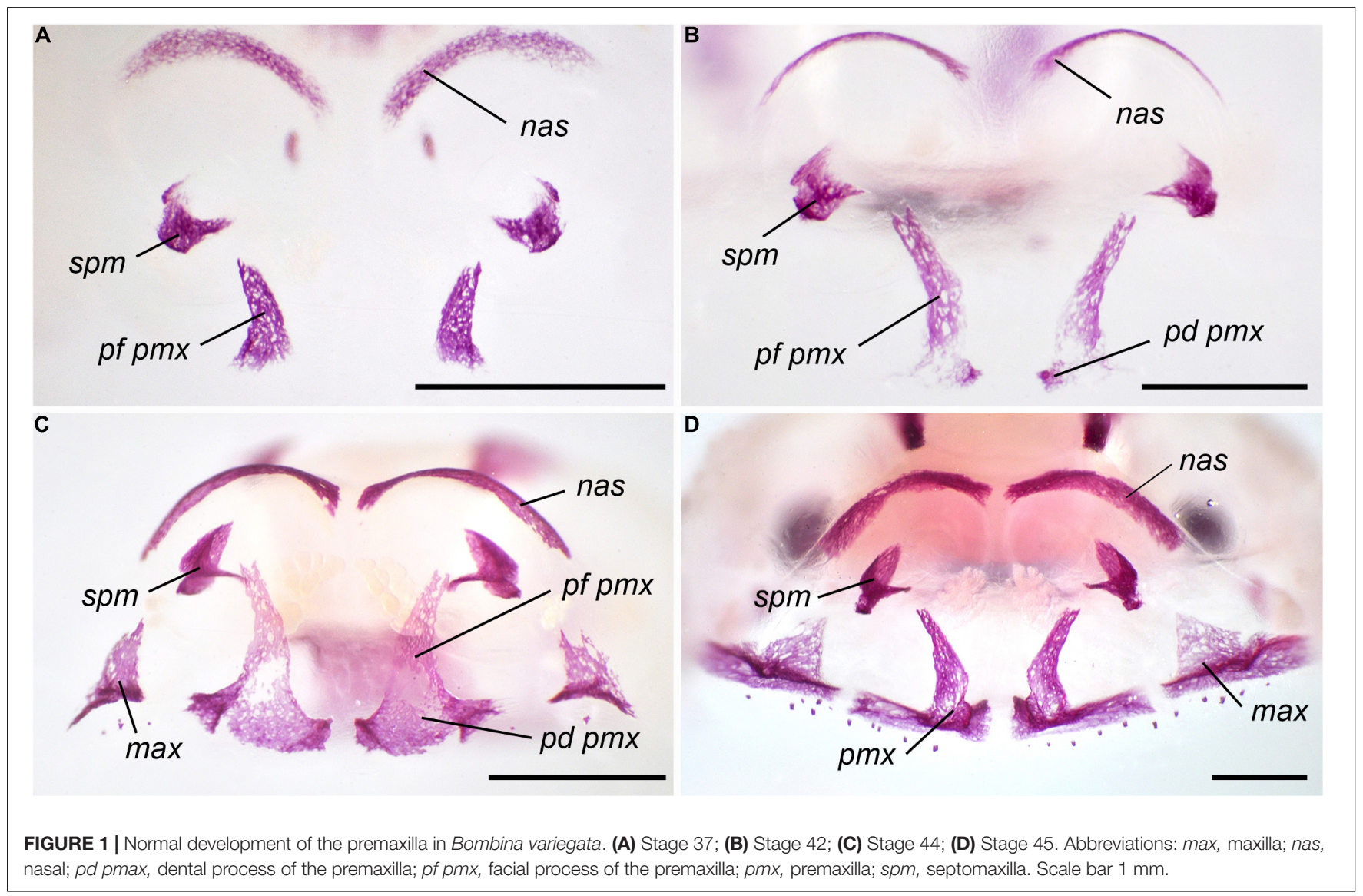

parasphenoid appear after the frontoparietals. The observed variability between Norm I and Norm II is limited mostly to temporal differences; thus, in Norm I, ossification starts on the 14th dph and is completed in 23 days, by $37 \mathrm{dph}$, in contrast to the 20th dph and 14 days, by $34 \mathrm{dph}$, respectively, in Norm II (Table 3). 
TABLE 3 | Timing (the earliest registration in dph) of cranial bones appearance in larval Bombina variegata under different experimental regimes.

\begin{tabular}{|c|c|c|c|c|c|c|c|c|}
\hline \multirow[t]{3}{*}{ Bone } & \multicolumn{5}{|c|}{ Experiment 2007} & \multicolumn{3}{|c|}{ Experiment 2019} \\
\hline & \multirow[t]{2}{*}{ Norm I } & \multicolumn{2}{|c|}{$\mathbf{T}_{3}$} & \multicolumn{2}{|c|}{ TU } & \multirow[t]{2}{*}{ Norm II } & \multicolumn{2}{|c|}{$\mathbf{T}_{3}$} \\
\hline & & $2 \times 10^{-10} M$ & $2 \times 10^{-9} M$ & $0.02 \%$ & $0.04 \%$ & & $2 \times 10^{-8} M$ early & $2 \times 10^{-8} \mathrm{M}$ late \\
\hline Parasphenoid & 14 & 14 & 14 & 17 & 22 & 22 & 17 & 22 \\
\hline Frontoparietal & 14 & 14 & 14 & 17 & 22 & 20 & 17 & 22 \\
\hline Exoccipital & 18 & 17 & 15 & 20 & 59 & 22 & - & 24 \\
\hline Premaxilla & 23 & 19 & 15 & 48 & - & 24 & 17 & 22 \\
\hline Septomaxilla & 26 & 22 & 18 & 48 & - & 26 & 17 & 22 \\
\hline Vomer & 28 & 19 & 15 & 52 & - & 28 & 18 & 24 \\
\hline Nasal & 28 & 23 & 18 & 52 & - & 28 & - & - \\
\hline Angulosplenial & 29 & 23 & 18 & 52 & - & 28 & 18 & 24 \\
\hline Squamosal & 29 & 25 & 21 & 52 & - & 28 & 18 & 24 \\
\hline Maxilla & 30 & 29 & 22 & 60 & - & 28 & 18 & 24 \\
\hline Dentary & 30 & 33 & 22 & 63 & - & 28 & 17 & 24 \\
\hline Quadratojugal & 32 & 33 & 27 & - & - & 32 & 18 & 24 \\
\hline Pterygoid & 33 & 34 & 26 & - & - & 34 & - & - \\
\hline Prootic & 33 & 34 & - & - & - & 34 & - & - \\
\hline Os thyroideum & 37 & - & - & - & - & 34 & - & - \\
\hline
\end{tabular}

\section{$\mathrm{T}_{3}$-Treated Tadpoles}

Changes in the timing and sequence of cranial bone appearance in $\mathrm{T}_{3}$-treated tadpoles are summarized in Tables 3,4 .

At the lowest $\mathrm{T}_{3}$ concentration, $2 \times 10^{-10} \mathrm{M}$, the timing of the appearance of the first skull bones, parasphenoid and frontoparietal, remains unchanged compared with the norm. Other ossifications normally arising in the midlarval, premtamorphic, and early metamorphic periods (exoccipital, premaxilla, septomaxilla, vomer, nasal, angulosplenial, and squamosal) appear somewhat precociously compared with the norm (Table 3). Additionally, they are slightly shifted to earlier developmental stages: the premaxilla and vomer appear in Stages 37-38, and the angulosplenial, squamosal, and nasal appear in Stages 39-40. Moreover, the sequence of bone appearance is somewhat altered: the vomer arises precociously, before the septomaxilla, nasal, and angulosplenial, thus changing its sequence position from 6-7 to 5 (Table 4). Bones normally appearing at late metamorphosis, in St. 43-46 (maxilla, dentary, quadratojugal, pterygoid, and prootic) form in the same sequence and at approximately the same time as in controls (Norm I), except for the os thyroideum, which fails to appear during the experiment.

At the higher $\mathrm{T}_{3}$ concentration of $2 \times 10^{-9} \mathrm{M}$, no changes in the timing and stage of the appearance of the parasphenoid and frontoparietals are detected, whereas the formation of all remaining cranial bones is strongly affected in both timing and sequence. They form faster than both in the norm and under $\mathrm{T}_{3} 2 \times 10^{-10} \mathrm{M}$ and mostly at earlier developmental stages. Thus, the premaxilla and vomer arise simultaneously with the slightly accelerated exoccipital at St. 37, followed during the same stage by the simultaneously forming septomaxilla, nasal, and angulosplenial and then squamosal, dentary and maxilla (St. 37-38). The appearance of the pterygoid varies within stages 38-40 and slightly anticipates the quadratojugal, thus changing its sequence position from 13 to 12 (Table 4). The prootic and os thyroideum do not form in this group by the end of metamorphosis. The developmental pattern of individual bones is somewhat affected: in the developing premaxilla, the dental process either almost immediately follows the facial process, or its separate anlage is not observed, and the premaxilla seems to appear as an entire bone. Often, the vomer develops from two separate ossifications, the medial and lateral centers. In single specimens, the nasal, squamosal, and pterygoid also ossify from two anlagen.

At the highest $\mathrm{T}_{3}$ concentration, $2 \times 10^{-8} \mathrm{M}$, beginning from early developmental stages (6 dph), the timing and sequence of bone appearance are strongly altered (Tables 3, 4). Unlike the norm, the first to appear are the premaxilla and dentary (Figure 2), which change their sequence positions from 4 and 11 , respectively, to 1-2 in both. They are closely followed by the frontoparietal (shifting from 1-2 to 3 ) and, almost immediately, by the parasphenoid and septomaxilla (shifting from 1-2 and 5 , respectively, to $4-5$ in both). The appearance of the vomer, greatly accelerated relative to the norm, is anticipated by the more or less simultaneous formation of squamosal, angulosplenial, maxilla (which fuses laterally to the premaxilla, Figure $\mathbf{3 A}$ ), and quadratojugal. By shifting its sequence position from 6-7 to 10 , the vomer becomes the last bone to form, since the remaining several dermal and endochondral bones fail to appear by the end of the experiment.

At $2 \times 10^{-8} \mathrm{M} \mathrm{T}_{3}$ beginning from the midlarval stages (15 dph), the appearance of the earliest bones normally arising at St. 36-37 (parasphenoid, frontoparietal, and exoccipital) remains mostly unchanged. Other bones display a marked acceleration of their appearance (Table 3) as well as alterations in the order of their appearance: the premaxilla 
TABLE 4 | Sequence of cranial bones appearance in larval Bombina variegata under different experimental regimes.

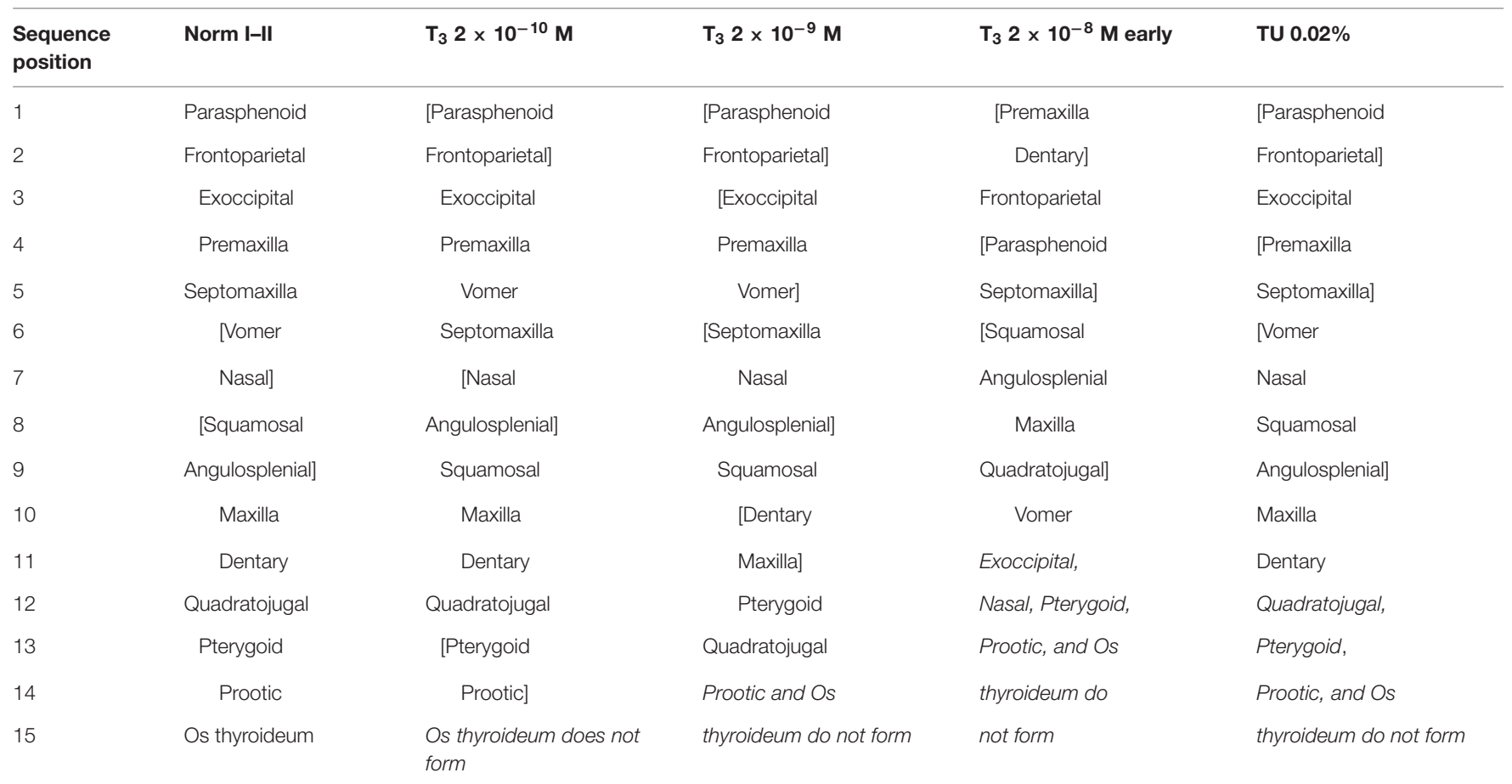

Bones in [brackets] appear simultaneously or the sequence of their appearance is not resolved.

A

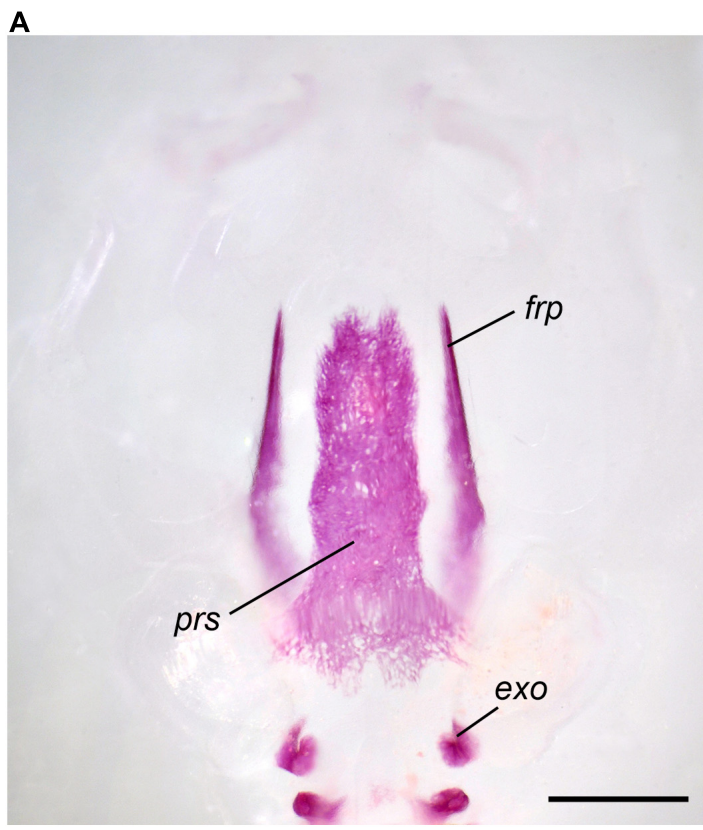

B

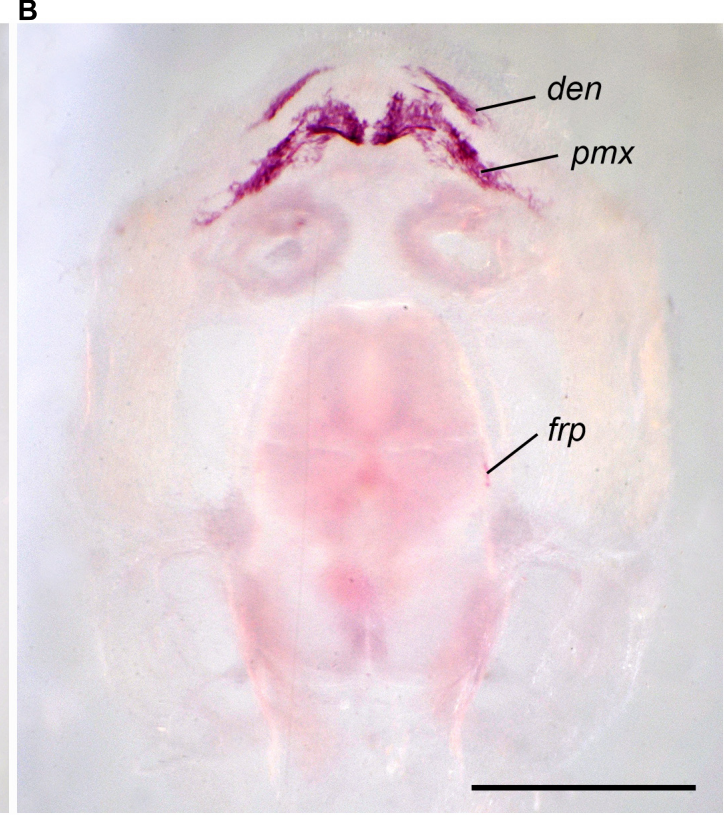

FIGURE 2 | First cranial bones to appear in Bombina variegata: (A) in norm II, Stage 37, 24 dph; (B) in $T_{3} 2 \times 10^{-8}$ M (early), Stage 35, 17 dph. Abbreviations: den, dentary; exo, exoccipital; frp, frontoparietal; pmx, premaxilla; prs, parasphenoid. Scale bar $1 \mathrm{~mm}$.

and septomaxilla immediately follow the parasphenoid and frontoparietal, thus appearing before the exoccipital. The squamosal, maxilla, angulosplenial, dentary, and quadratojugal arise nearly simultaneously, followed immediately by the vomer. The remaining bones (nasal, prootic, pterygoid, and os thyroideum) do not appear during the experiment. Some bones display changed pattern of development. Thus, in contrast to the norm, the formation of the premaxilla begins with its dental part and not with the facial process (Figure 4). Additionally, the premaxilla fuses with the maxilla 

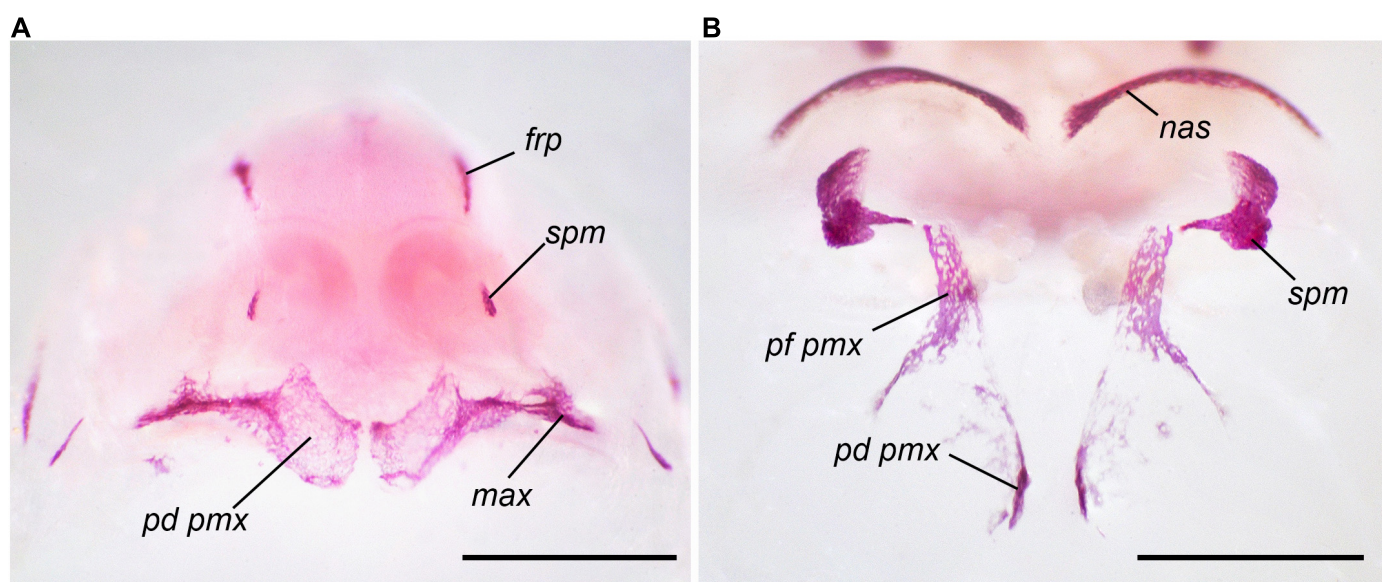

FIGURE 3 | Development of the premaxilla in Bombina variegata: (A) in $\mathrm{T}_{3} 2 \times 10^{-8} \mathrm{M}$ (early), Stage 35, $18 \mathrm{dph}$; (B) in TU $0.02 \%$, Stage 43, 75 dph. For abbreviations, see Figures 1, 2. Scale bar $1 \mathrm{~mm}$.
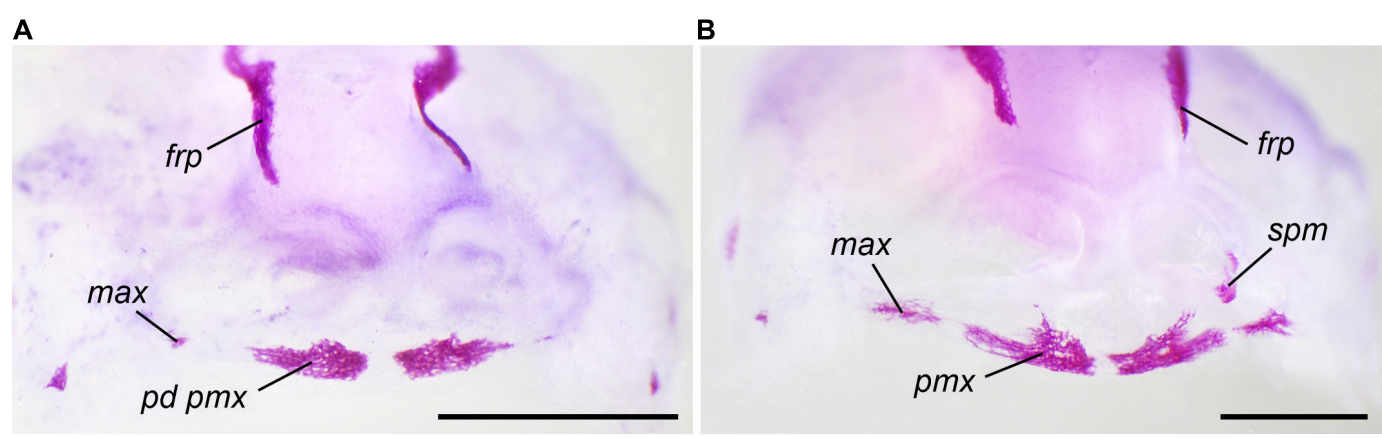

FIGURE 4 | Development of the premaxilla and maxilla in Bombina variegata at $\mathrm{T}_{3} 2 \times 10^{-8}$ M (late): (A) Stage 36, 22 dph (B) Stage 37,24 dph. For abbreviations, see Figures 1, 2. Scale bar $1 \mathrm{~mm}$.

on each side of the skull to form a paired compound bone that expands laterally and occupies the entire upper jaw. The facial processes of both the premaxilla and maxilla remain low and underdeveloped. Multiple centers of ossification are detected in the developing parasphenoid and frontoparietal bones (Figure 5).

\section{TU-Treated Tadpoles}

At TU $0.02 \%$, bones forming in the midlarval, premetamorphic and early metamorphic periods appear in the same sequence as in the norm, but the timing of their appearance is delayed (Tables 3, 4). Bones normally appearing close to metamorphosis (quadratojugal, pterygoid, prootic, and os thyroideum) fail to form even after four months of the experiment. Certain dermal bones display multiple ossification centers in their development; e.g., two ossified anlagen are usually detected in the angulosplenial (the medial and the lateral one); in the premaxilla, the facial process and dental portion remain separate almost until the end of the experiment (Figure 3B).

At TU $0.04 \%$, only three of the first appearing bones (parasphenoid, frontoparietal, and exoccipital) arise, and the appearance of the last is strongly delayed relative to the norm (Table 3). Multiple ossification centers usually appear in the developing frontoparietal and parasphenoid.

\section{Effect of $\mathrm{T}_{3}$-Treatment on the Larval Chondrocranium}

The pattern of remodeling of the larval chondrocranium and hyobranchium in $B$. variegata at $2 \times 10^{-8} \mathrm{M} \mathrm{T}_{3}$ (Experiment II, treatment started at 6 and $15 \mathrm{dph}$ ) is mostly consistent with that in TH-treated B. orientalis, described in detail by Hanken and Summers (1988).

Tadpoles sampled after 5, 7, 9, and 11 days of $\mathrm{T}_{3}$-treatment display gradual metamorphic transformations of the larval cartilaginous elements of the skull and hyobranchium well before such remodeling starts in the norm. The timing of these transformations does not depend upon the stage and time of the onset of the treatment. In both groups (with early and late beginning of $\mathrm{T}_{3}$-administration), the first signs of the remodeling (partial resorption of the medial part of the suprarostral cartilages and the rostral ends of the trabecular horns, and the disappearance of the joint between the infrarostral and Meckelian cartilages) are clearly apparent 

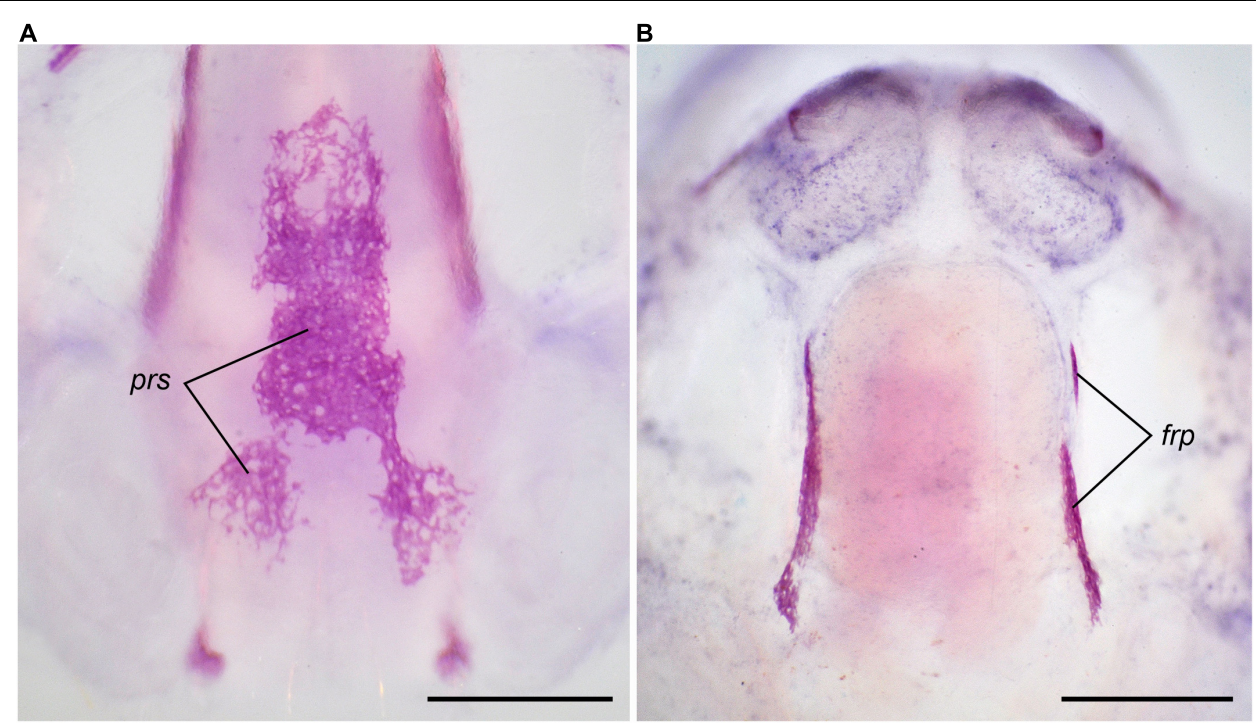

FIGURE 5 | Multiple ossification centers in Bombina variegata at $\mathrm{T}_{3} 2 \times 10^{-8} \mathrm{M}$ (late): (A) in the parasphenoid, Stage 37, 24 dph (B) in the frontoparietal, Stage 36 , $22 \mathrm{dph}$. For abbreviations, see Figures 1, 2. Scale bar $1 \mathrm{~mm}$.

after 5 days of treatment (11 dph and $20 \mathrm{dph}$, respectively). After 9 days of $\mathrm{T}_{3}$-administration, in comparison to the norm (Figures 6A,B) of the same age, the $\mathrm{T}_{3}$-treated tadpoles display a transitional stage of cartilage remodeling normally characteristic of early metamorphic St. 42-43. In them, the suprarostral cartilage is mostly resorbed, retaining only the rudiments of the lateral alae; the trabecular horns are strongly eroded; palatoquadrate displays partial erosion of the anterior quadratocranial commissures and ascending processes; a thin laminar cartilage appears on the place of the future roof of the nasal capsule, forming the primordium of the cartilaginous tectum nasi; infrarostral cartilage fuses with Meckelian cartilage, forming a single cartilaginous mandible (Figure 6C); in the hyobranchium, the basihyal (copula I) is resorbed, and the ceratobranchial cartilages become thinner and lose the transverse commissures (Figure 6D). After 11 days of $\mathrm{T}_{3}$-treatment, the suprarostral cartilage and trabecular horns disappear entirely, and the lower jaw achieves its metamorphic shape. However, remodeling of the palatoquadrate is somewhat delayed; although the subocular arcs are eroded, the anterior quadratocranial commissures and ascending processes still persist; therefore, the joint with the Meckelian cartilage is not displaced backward, and the transformed lower jaw protrudes forward of the upper jaw (Figure 6E). In the hyobranchium, the resorption of the ceratohyal is in progress (Figure 6F).

\section{Development of the Postcranial Bony Skeleton Under Different Hormonal Regimes}

In normal development, ossification of the axial skeleton begins with the basal parts of neural arches II-IV, more or less simultaneously with the formation of the first cranial bones at early St. 36 (Table 2). Neural arch of the vertebra I starts to ossify with some delay, when the arches of vertebrae II$\mathrm{V}$ are already ossified. During the midlarval period, all neural arches of the presacral (I-VIII) and sacral (IX) vertebrae become ossified, and signs of ossification in the centra appear. By the end of St. 38, the neural arch of postsacral vertebra $\mathrm{X}$ ossifies simultaneously with the appearance of a thin elongated hypochord plate ventral to the notochord. During the premetamorphic period, the neural arch of the second postsacral vertebra (XI) ossifies and start to slightly elongate in the posterior direction. Soon, the neural arches of vertebrae $\mathrm{X}$ and XI fuse together, forming the primordium of the coccyx. By the end of metamorphosis, the coccygeal vertebrae fuse with the hypochord, completing the formation of the urostyle. During the metamorphic stages, the ribs fused to vertebrae II-IV progressively ossify.

Under $\mathrm{T}_{3}$-treatment, elements of the axial skeleton ossify earlier relative to the norm (Table 5). Under TUtreatment, a delay in the ossification of the vertebrae is observed; the most delayed vertebrae under TU $0.02 \%$ are vertebrae X-XI forming the coccyx. Under TU $0.04 \%$, the retardation of the development of vertebrae $\mathrm{I}-\mathrm{X}$ is more pronounced. Ossifications normally appearing in premetamorphic and metamorphic periods (hypochord, vertebra XI, and ribs) do not arise at TU $0.04 \%$ until the end of the experiment and the urostyle does not form (Table 5).

In the normal development of the appendicular skeleton, forelimb formation is slightly delayed relative to hindlimb formation (see Table 5) but usually occurs at the same developmental stages (Table 2). Most bony elements of the pectoral and pelvic girdles form during the midlarval stages except for the ischium, which appears only close to metamorphosis, after all foot and hand phalanges are already more or less ossified. 


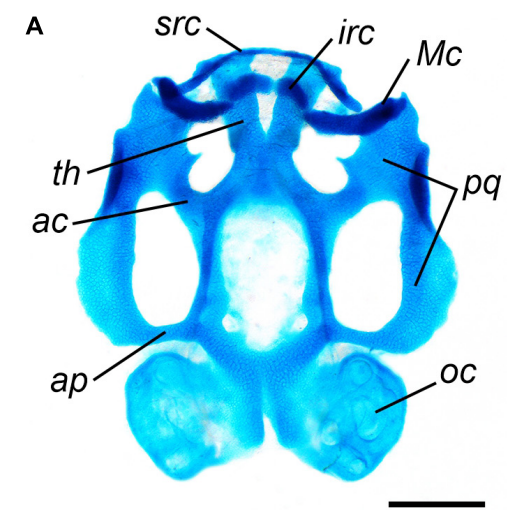

B

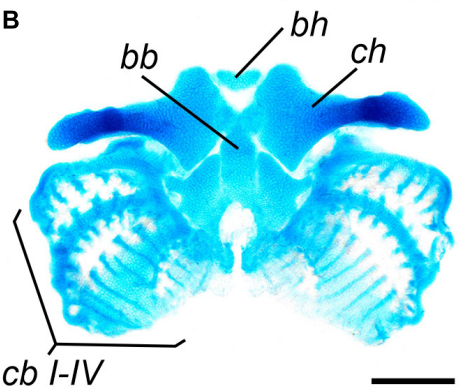

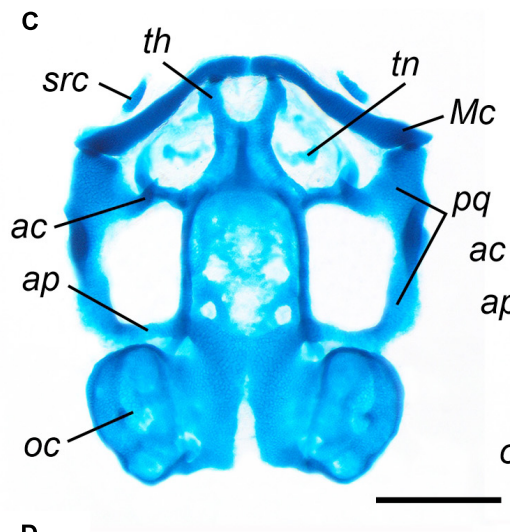

D

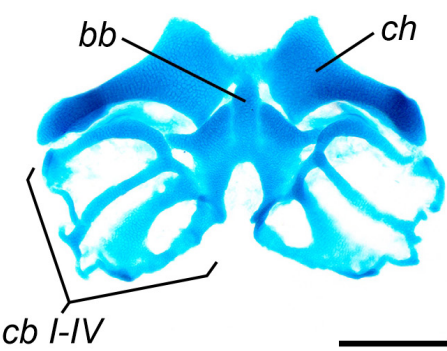

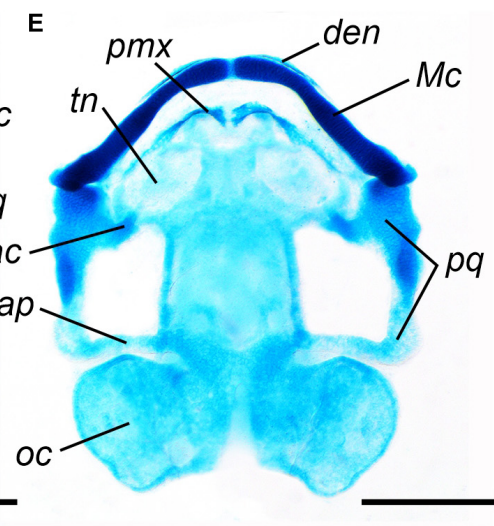

$\mathbf{F}$

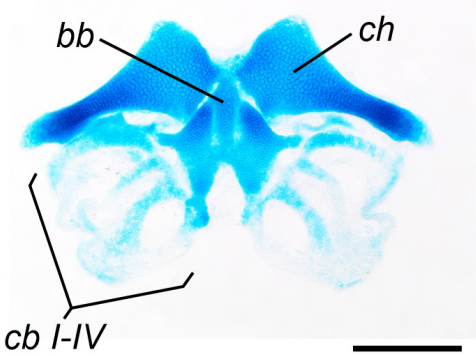

FIGURE 6 | Larval chondrocranium and hyobranchium of Bombina variegata in normally developing and TH-treated tadpoles: (A,B) norm, Stage 35, 15 dph; (C,D) after 9 days of treatment with $\mathrm{T}_{3} 2 \times 10^{-8} \mathrm{M}$, limb development corresponding to Stage $35,15 \mathrm{dph}$; (E,F) after 11 days of treatment with $\mathrm{T}_{3} 2 \times 10^{-8} \mathrm{M}$, limb development corresponding to Stage 35, $17 \mathrm{dph}$. Abbreviations: ac, anterior commissure of palatoquadrate; ap, ascending process of palatoquadrate; $b b$, basibranchial; $b h$, basihyal; $c b$, ceratobranchials; $c h$, ceratohyal; den, dentary; irc, infrarostral cartilage; Mc, Meckelian cartilage; oc, otic capsule; pmx, premaxilla; pq, palatoquadrate; src, suprarostral cartilage; th, tectum nasi; th, trabecular horns. Scale bar $1 \mathrm{~mm}$.

At $2 \times 10^{-8} \mathrm{M} \mathrm{T}_{3}$ beginning from $6 \mathrm{dph}$, appendicular and axial skeleton do not show signs of ossification before the end of the experiment. At $2 \times 10^{-9} \mathrm{M} \mathrm{T}_{3}$, ossification of all elements of the appendicular skeleton is accelerated compared with the norm (Table 5). In contrast, under TU-treatment (0.02\%), the latter is retarded. Higher TU concentration $(0.04 \%)$ has a more profound effect on more later-forming appendicular ossifications (such as first foot and hand phalanges); the last appearing bones, normally ossifying close to metamorphosis, such as distal phalanges of digits I on the hand and foot and the ischium, do not form during the experiment. If these bones appear (especially the autopodial elements), they remain rudimentary as thin ossified rings in the middle of the cartilaginous matrices. Among elements of the pectoral girdle, the endochondral scapula and coracoid display a more profound reaction to TU-treatment, resulting in some changes in the sequence of bone appearance.

\section{DISCUSSION}

\section{The Role of Thyroid Hormones in Skeletal Development in Bombina variegata \\ Normal Development of the Skeleton}

Overall, the revealed ossification sequence in the skull and postcranial skeleton during the normal development of
B. variegata is similar to that of $B$. orientalis studied by Hanken and Hall (1984, 1988a) and Maglia and Púgener (1998). The degree of variability in the timing and sequence of cranial bone appearance is comparable with that found in B. orientalis (Hanken and Hall, 1988a). On a large-scale comparison within anurans with a biphasic life history, B. variegata displays a rather typical cranial ossification sequence, with the frontoparietal, parasphenoid, and exoccipital arising first and dentary, quadratojugal, and pterygoid are among the last bones to arise (Trueb and Alberch, 1985; Weisbecker and Mitgutsch, 2010). At the same time, the unusually early appearance of the vomer and late appearance of the prootic in comparison with the majority of studied anuran species may be considered characteristic features of the genus Bombina.

\section{Effects of $\mathrm{T}_{3}$ - and TU-Treatment on Cranial Development in Bombina variegata}

In all experimental groups, the sequence of skull ossification is more or less truncated. Actually, the sole cranial ossifications in $B$. variegata to form under all hormonal regimes are two dermal bones, frontoparietal and parasphenoid. In most cases, they appear more or less simultaneously and occupy the first two positions in the ossification sequence (except at the highest $\mathrm{T}_{3}$ concentration), thus displaying only a limited reaction to the TH-level changes: their development is slightly accelerated by a high $\mathrm{TH}$-dosage and slightly retarded 
TABLE 5 | Timing (the earliest registration in dph) of the postcranial skeletal elements appearance in larval Bombina variegata under different experimental conditions (Experiment I).

\begin{tabular}{|c|c|c|c|c|}
\hline $\begin{array}{l}\text { Skeletal } \\
\text { elements }\end{array}$ & Norm I & $\mathrm{T}_{3} 2 \times 10^{-9} \mathrm{M}$ & TU $0.02 \%$ & TU $0.04 \%$ \\
\hline & \multicolumn{4}{|c|}{ Limbs and limb girdles } \\
\hline Femur & 14 & 12 & 22 & 22 \\
\hline Fibula, tibia & 14 & 13 & 22 & 22 \\
\hline Tarsals & 17 & 14 & 25 & 24 \\
\hline Metatarsals & 18 & 14 & 30 & 30 \\
\hline Ilium & 19 & 14 & 30 & 30 \\
\hline $\begin{array}{l}\text { First foot } \\
\text { phalanges }\end{array}$ & 19 & 17 & 38 & 51 \\
\hline $\begin{array}{l}\text { All foot } \\
\text { phalanges }\end{array}$ & 23 & 19 & 48 & - \\
\hline Ischium & 28 & 25 & 52 & - \\
\hline Humerus & 18 & 14 & 27 & 22 \\
\hline Ulna, radius & 18 & 14 & 30 & 24 \\
\hline Cleithrum & 19 & 15 & 37 & 45 \\
\hline Coracoid & 19 & 15 & 38 & 79 \\
\hline Clavicle & 19 & 15 & 37 & 45 \\
\hline Scapula & 19 & 18 & 38 & 116 \\
\hline Metacarpals & 19 & 15 & 37 & 45 \\
\hline $\begin{array}{l}\text { First hand } \\
\text { phalanges }\end{array}$ & 19 & 17 & 38 & 51 \\
\hline \multirow{2}{*}{$\begin{array}{l}\text { All hand } \\
\text { phalanges }\end{array}$} & 24 & 19 & 48 & - \\
\hline & \multicolumn{4}{|c|}{ Axial skeleton } \\
\hline $\begin{array}{l}\text { Presacral } \\
\text { vertebrae } \\
\text { |-VIII }\end{array}$ & 17 & 14 & 24 & 27 \\
\hline Sacral IX & 19 & 14 & 24 & 37 \\
\hline Postsacral X & 19 & 14 & 33 & 37 \\
\hline Postsacral XI & 23 & 15 & 53 & - \\
\hline Hypochord & 23 & 15 & 38 & - \\
\hline Centra & 23 & 18 & 38 & - \\
\hline Ribs & 25 & 22 & 52 & - \\
\hline Urostyle & 35 & 27 & - & - \\
\hline
\end{tabular}

by TU. All other bones are more affected by $\mathrm{T}_{3}$ - or $\mathrm{TU}$ treatment. The formation of the exoccipital is somewhat accelerated under $\mathrm{TH}$-action depending upon the dosage and retarded under TU-treatment and very significantly at the high goitrogen dosage. At the highest $\mathrm{T}_{3}$-dosage and early onset of treatment, this bone fails to form. Although exoccipital is among the early ossifications and normally appears 3rd in the ossification sequence, it probably requires sufficient differentiation of the preceding cartilaginous structures. It is noteworthy that the development in this experimental group is abbreviated to $20 \mathrm{dph}$, i.e., terminating earlier than the exoccipital forms in the norm. When exposure to high dosages of $\mathrm{T}_{3}$ begins later, at mid-larval stages, the exoccipital appears, although it is preceded by some dermal ossifications (premaxilla and septomaxilla), which develop later in the norm.
The latest bones in the normal sequence, the dermal quadratojugal and pterygoid and the endochondral prootic and os thyroideum, fail to appear under partial inhibition of skull development with lower TU- dosage when craniogenesis is blocked at the mid-metamorphic stage. Under $\mathrm{T}_{3}$-treatment, the number of bones that fail to appear increases as the hormone dosage increases (Table 4); presumably, they do not have sufficient time to form because of the general shortening of larval development, especially under high $\mathrm{T}_{3}$ dosages. Other cranial bones display dosage-dependent acceleration of their development under $\mathrm{T}_{3}$-treatment and retardation under moderate TU-inhibition.

A relatively low dosage of $\mathrm{T}_{3}\left(2 \times 10^{-10} \mathrm{M}\right)$ causes some acceleration of the formation of bones appearing at the initial stages of craniogenesis (except for the earliest parasphenoid and frontoparietal) but does not affect the appearance of bones arising in its final stages (from Stage 43 during normal development). This observation suggests that this concentration of exogenous $\mathrm{T}_{3}$ raises internal $\mathrm{TH}$ levels in larval tissues above the normal physiological level characteristic of the midlarval and premetamorphic stages and stimulates accelerated skull ossification. At the same time, this level apparently does not exceed the $\mathrm{T}_{3}$ peak characteristic of the stages at which drastic metamorphic rearrangements begin; therefore, it does not affect the formation of ossifications occurring at the metamorphic period of development. A higher concentration of $\mathrm{T}_{3}\left(2 \times 10^{-9}\right.$ $\mathrm{M})$ causes a greater acceleration of the development of most cranial bones, as well as a more marked alteration of their normal ossification sequence. Thus, in normal development in $B$. variegata, the vomer and nasal arise simultaneously, but the vomer responds more drastically to the action of exogenous $\mathrm{T}_{3}$ : its formation is more accelerated, and it visibly shifts to earlier positions in the sequence. Nasal, although accelerated in development, lags behind that of the vomer. The highest concentration of $\mathrm{T}_{3}\left(2 \times 10^{-8} \mathrm{M}\right)$ has the most profound effect on craniogenesis, causing the precocious formation of most ossifications (including the earliest ones) compared with the norm and the most significant alterations of the normal sequence, with even relatively late bones (such as dentary) shifting to early positions. This indicates that bones arising after the beginning of metamorphosis strongly depend on THs in their development, but the degree of TH-responsivity varies among bones. It is worth noting that even different constituent parts of certain bones may exhibit different reactions to $\mathrm{TH}$-changes. In the developing premaxilla, the dental process appears precociously under high $\mathrm{T}_{3}$ concentrations and postpones its appearance under TUtreatment. Its facial process develops in TU-treated tadpoles and does not show evident acceleration in TH-treated tadpoles.

All cranial bones, which display the most profound reaction to TH-level changes, are associated with the palatoquadrate and Meckelian cartilages, and all of them both in normal and THinduced development appear only after these cartilages start to remodel. This pattern of development suggests the occurrence of a certain interplay between dermal bones and adjacent cartilages. Three hypotheses may be proposed. First, it is precociously induced cartilage remodeling that induces the precocious bone development. Second, it is THs that precociously induce bones, 
whereas cartilages provide only a necessary framework for them. Third, both cartilage and THs are involved in the induction of bone appearance. To elucidate the main inducing factor, further studies are needed.

Observation of the development of other bones supports the occurrence of a certain cartilage-bone interplay. Normally, in the premaxilla, its facial process appears first, followed by the dental process. In $\mathrm{TH}$-treated tadpoles, the dental process precedes the facial process. In anurans, the developing facial process of the premaxilla abuts the superior prenasal cartilage appearing at prometamorphosis (Roček, 2003; Pugener and Maglia, 2007). In our experiment, early tadpoles were $\mathrm{TH}$-treated before the formation of this cartilage resulting in the delayed appearance of the facial process or its absence. Also, in anurans, bones associated with the nasal capsule always ossify after the adjacent parts of the capsule are chondrified (Pugener and Maglia, 2007). The floor of the nasal capsule (solum nasi) chondrifies early, whereas chondrification of its roof (tectum nasi) is a late event that is only moderately accelerated by exogenous $\mathrm{TH}$. Consequently, although normally the nasal and vomer in $B$. variegata appear simultaneously on the tectum nasi and solum nasi, respectively, in the TH-treated larvae the vomer greatly precedes the nasal. The ascending process of the maxilla also remains rudimentary at high $\mathrm{T}_{3}$ dosages, presumably due to the delayed development of the lateral wall of the nasal capsule invested by this process.

\section{The Role of Thyroid Hormones in the Skeletogenesis of Urodelans and Anurans \\ Bony Skull}

Urodelans, experimentally studied to date, display a consistent pattern of cranial ossification. First to appear are toothbearing bones (premaxilla, dentary, vomer, coronoid, and palatopterygoid), followed by midlarval bones (frontal, parietal, orbitosphenoid, and quadratojugal), and then late-appearing bones (maxilla, nasal, prefrontal, and septomaxilla), which arise in the premetamorphic stages or during metamorphosis. At metamorphosis, the salamander skull undergoes considerable remodeling: (i) the coronoid and palatine portion of the palatopterygoid (or palatopterygoid entirely in plethodontids) resorb, and (ii) the larval vomer transforms into the adult vomer. Anteriorly, vomer forms outgrowths extending toward the premaxilla and maxilla. Posteriorly, the vomer develops a tooth-bearing caudal process (vomerine bar), extending along a lateral edge of the parasphenoid. In plethodontids, this bar transforms into a separate bony element bearing the parashenoid tooth patch.

In S. keyserlingi, A. mexicanum, L. vulgaris, and P. waltl, the first bones to appear arise at the same time and sequence under different hormonal conditions (Smirnov and Vassilieva, 2003, 2005; Smirnov et al., 2011, 2020). Midlarval bones display some acceleration and retardation under $\mathrm{TH}$ and $\mathrm{TU}$ treatments, respectively. The effect of $\mathrm{TH}$-changes is profound in the late-appearing dermal bones, maxilla, nasal, and prefrontal (and lacrimal and septomaxilla in S. keyserlingi and A. mexicanum)

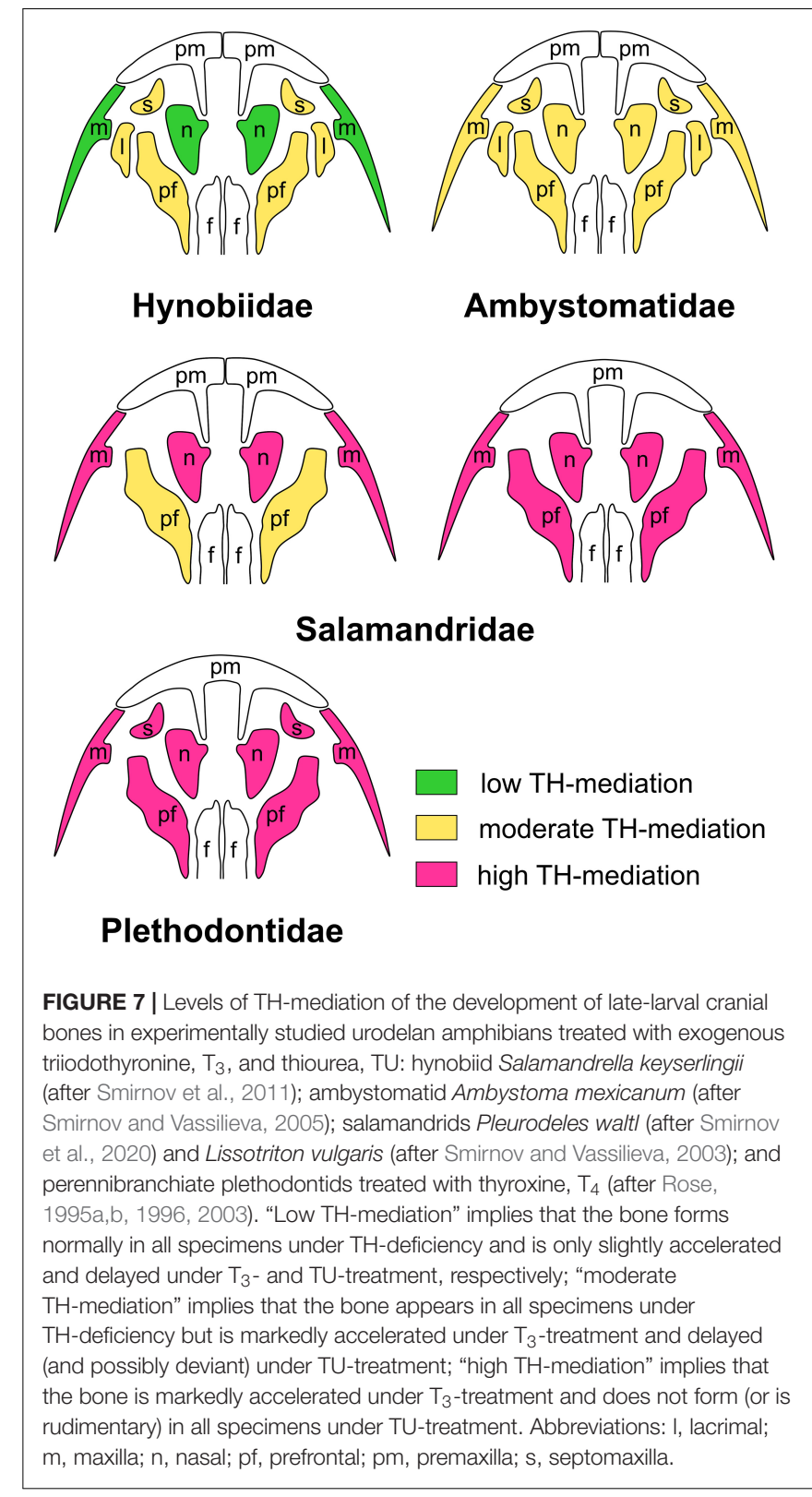

(Figure 7). The most evident reaction is revealed in metamorphic palate remodeling and coronoid resorption. These events are greatly accelerated in TH-treated animals and fail to occur in TU-treated animals. The latter, even after a year and half of the experiment, retain the palatopterygoid and coronoid accompanied by a larval vomer without outgrowths toward the upper jaw bones and posterior vomerine bar. Earlier, Rose (1995a,b) revealed late-appearing bones (maxilla, nasal, prefrontal, and septomaxilla) and metamorphic transformation of the vomer and resorption of the palatopterygoid and coronoid to be greatly accelerated under TH-treatment in the plethodontid Eurycea bislineata. As in our experiments, the degree of acceleration depended upon the applied THdosage and the stage of larval development at which animals 
were TH-treated. However, the effect of thyroid deficiency on cranial development has not been studied and remains unknown in plethodontids.

These findings indicate that (i) THs are involved in the cranial ossification of salamanders and (ii) skull development is accompanied by changes in the degree of TH-responsivity of cranial bones. The appearance of early bones seems to be not reactive to $\mathrm{TH}$, and midlarval bones display slight $\mathrm{TH}$ responsivity, which becomes evident in late-appearing bones (maxilla, nasal, prefrontal, and septomaxilla) and obligate for metamorphic cranial remodeling. Interestingly, whereas the appearance of early bones does not depend upon TH-level, their further development and morphological differentiation become TH-inducible. Thus, in $P$. waltl, changes in the TH-level do not affect the timing of the premaxillar appearance, while later formation of its outgrowth toward the vomer is strictly induced by THs (Smirnov et al., 2020).

In our experiments, because of different reactions to $\mathrm{TH}$-changes, $\mathrm{T}_{3}$-treated salamanders displayed changes in the sequence of bone appearance: highly TH-responsive bones, normally appearing at the late larval stage or at metamorphosis, arose precociously and preceded the appearance of bones, which normally arise prior to them. In nature, a similar phenomenon seems to occur in ambystomatids. The developing neotenic A. mexicanum differs from closely related metamorphosing congeneric A. tigrinum in (i) a precocious TH-surge (Larras-Regard, 1985; Rosenkilde, 1985) and (ii) a precocious appearance of the TH-mediated nasal bone (Rose, 2003; Smirnov and Vassilieva, 2005).

Additionally, in our experiments, because of different bone reactions to $\mathrm{TH}$-changes, $\mathrm{TH}$-treated animals exhibited a mixture of early larval and metamorphic features. In salamanders, changes in the TH-level do not influence the timing and rate of the early larval period of development of the coronoid, palatopterygoid and vomer. Their further metamorphic transformations are obligatory $\mathrm{TH}$-mediated and are greatly accelerated under TH-treatment. Consequently, $\mathrm{TH}$-induced precocious transformation begins when the $\mathrm{TH}$ independent period of these bones' development is not yet completed. The earlier exogenous THs are applied, the more underdeveloped these bones are at the beginning of metamorphic transformation. This resulted, e.g., in the appearance of vomer consisting of the underdeveloped larval (anterior) portion and adult (posterior) portion.

In nature, a similar developmental pattern was observed in the direct-developing plethodontid Desmognathus aeneus (Marks, 2000) (see below).

Although late-appearing bones display obvious reactions to TH-changes in all salamanders studied in this respect, "degree" of their reaction differs. Thus, under a similar TH-treatment, they show moderate acceleration in S. keyserlingi but considerable acceleration in L. vulgaris and P. waltl. Similar differences were recorded in TU-treated salamanders. In S. keyserlingi, THdeficiency results in the postponed appearance of these bones. In $L$. vulgaris and $P$. waltl under TH-deficiency, the same bones are greatly delayed in appearance and remain rudimentary or fail to appear at all. A similar phenomenon is displayed by neotenic perennibranchiate plethodontids, which, because of the likely thyroid dysfunction, fail to metamorphose and retain larval cranial morphology: they lack late-appearing bones (maxilla, nasal, prefrontal, and septomaxilla) and palate remodeling (Rose, 1995c, 1996). However, these events (at least some of them) occur under exogenous TH-treatment (Rose, 1995a, 1996, 2003). In summary, these observations indicate that the same bones differ in their TH-reactivity: bones that are rather moderately $\mathrm{TH}-$ reactive in the basal salamander $S$. keyserlingi are TH-inducible in more derived urodelans.

Observations of $B$. variegata show that the involvement of THs in the regulation of skeletal development in anurans largely follows the same patterns that have been revealed in urodelans, especially with regard to the bony skull. In both salamanders and frogs, THs play a key role in the realization of the complete craniogenesis sequence: when larvae develop under the TH-deficiency, this sequence is truncated via the underdevelopment of late ossifications normally forming during the premetamorphic phase or metamorphic climax. Additionally, the involvement of THs in skull bones development become enhanced in both urodelans and anurans during ontogeny: while the TH excess or deficiency have only a regulatory impact (if ever) on the development of the earliest bones in the cranial ossification sequence, affecting the timing of their appearance, the later bones appearing at metamorphosis are strictly $\mathrm{TH}-$ inducible. Cranial bones that form normally in the stages when the level of endogenous THs is low show the least TH-reactivity (Figure 8). Bones, which normally develop closer to and/or during the metamorphic climax, are TH-sensitive: they do not develop at reduced TH-levels, while their appearance is markedly accelerated when the TH-level is increased. These bones require higher TH-levels for their development, and the closer to the metamorphic climax they appear, the higher the level.

Induced $\mathrm{TH}$-changes may cause similar changes in the developmental pattern of the same bones in frogs and salamanders. Thus, under high TH-levels, the premaxilla and maxilla tend to fuse in L. vulgaris (Smirnov and Vassilieva, 2003), P. waltl (Smirnov et al., 2020), and B. variegata (this study; see Figure 3A). In both urodelans and anurans, constituent parts of the same bone may exhibit different reactions to changes in TH-levels, as exemplified by the premaxilla in P. waltl (Smirnov et al., 2020) and B. variegata (this study). Additionally, under TH-changes, in both anurans and urodelans, the appearance of multiple ossification centers was observed in bones normally developing from the sole center. For example, in $P$. walt specimens with craniogenesis suppressed by the TU, the nasal is often represented by numerous ossicles (Smirnov et al., 2010, 2020). In anurans, under TU- and $\mathrm{T}_{3}$-treatment, multiple ossification centers were recorded in the frontoparietal, parasphenoid, vomer, angulosplenial, premaxilla, pterygoid, and others (Smirnov and Vassilieva, 2009). Presumably, this phenomenon is related to the induced alterations in the rate of differentiation, mineralization, and fusion of bone primordia caused by changes in the normal hormonal regime. In some cases, it confirms the complex evolutionary origin of the bone. In particular, in urodelans, the frontal was shown to have originated via fusion of the three separate ossification 

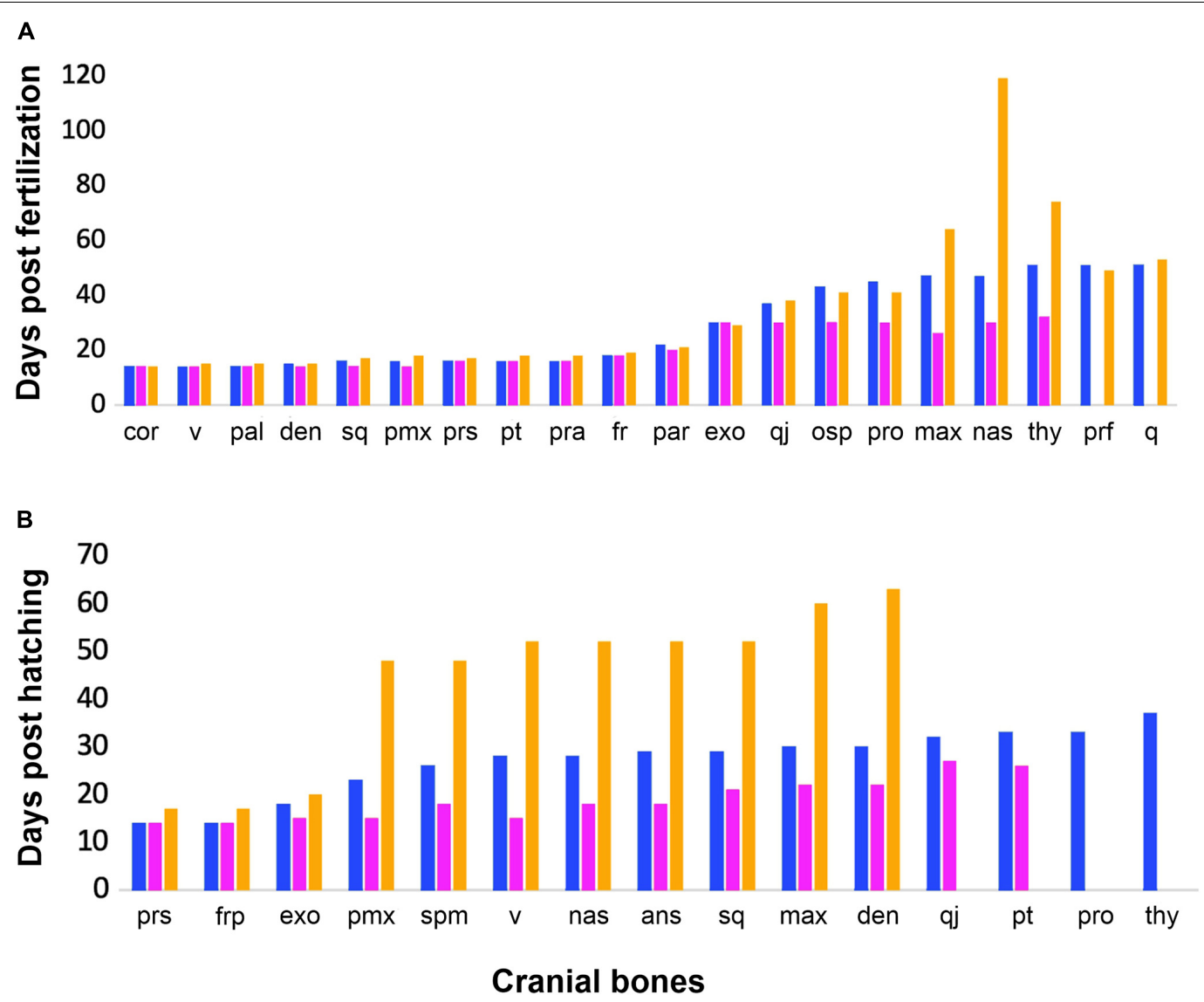

Norm $\quad T_{3} 2 \times 10^{-9} \mathrm{M} \square$ TU $0.02 \%$

FIGURE 8 | Timing of cranial bones development (earliest appearance) under same experimental hormonal regimes (in norm, under $\mathrm{T}_{3}$ and TU-treatment), (A) in Pleurodeles walt (after Smirnov et al., 2020) and (B) in Bombina variegata (this study). Abbreviations: cor, coronoid; den, dentary; exo, exoccipital; fr, frontal; max, maxilla; nas, nasal; osp, orbitosphenoid; pal, palatine; par, parietal; pmx, premaxilla; pra, prearticular; prf, prefrontal; pro, prootic; prs, parasphenoid; pt, pterygoid; q quadrate; qj, quadratojugal; sq, squamosal; thy, os thyroideum; v, vomer.

centers (Lebedkina, 1979, 2004). In B. variegata, formation of the frontoparietal from several early fusing anlagen was also confirmed by histological studies (Čihák et al., 2003).

Sporadic individual variability in the number of ossification centers observed in the developing bones in anurans (Wiens, 1989; Hall and Larsen, 1998; Banbury and Maglia, 2006) seems to result from individual changes in thyroid axis function.

\section{Appendicular Skeleton}

Experimental studies of the impact of THs on the development of the appendicular skeleton in urodelans are rather scarce. Brown (1997) demonstrated that exogenous $\mathrm{T}_{4}$ promotes accelerated limb elongation in axolotl, but did not report the effect of THs on the timing of limb bone ossification; the various goitrogens in this study were found to not interfere with limb development. In Lissotriton vulgaris, the timing of limb and limb girdle formation under exogenous $\mathrm{T}_{3}$ - and TU-treatment does not differ from the norm (Smirnov and Vassilieva, 2003). In contrast, in $B$. variegata, all ossifications of the appendicular skeleton display some TH-responsivity that is displayed in the timing of their appearance (Figure 9). Moreover, treatment with a high dosage of TU inhibits the ossification of the latest elements of the limb skeleton, i.e., the last phalanges of the fingers and toes and the ischium. However, the development of the appendicular skeleton is clearly less TH-controlled than that of the skull: if high TU-dosages block cranial ossification at rather early larval stages, the ossification of the limb skeleton progresses much further to an almost complete metamorphic set of bones. In parallel, under treatment with high $\mathrm{T}_{3}$-dosages from early larval stages, tadpoles display an obvious dissociation between head and limb development resulting in the appearance of animals with a mixture of a metamorphosing skull and hyobranchium and early-larval limbs.

Previous studies have shown that in anurans, THs are strictly required for normal limb formation (Brown et al., 2005). THs participate in the differentiation of limb cartilage and accelerate limb bone ossification (Kemp and Hoyt, 1969; Brown et al., 2005). However, it is not clear whether all stages of limb skeleton development are TH-dependent. On the one hand, experiments show that under TH-deficiency caused 

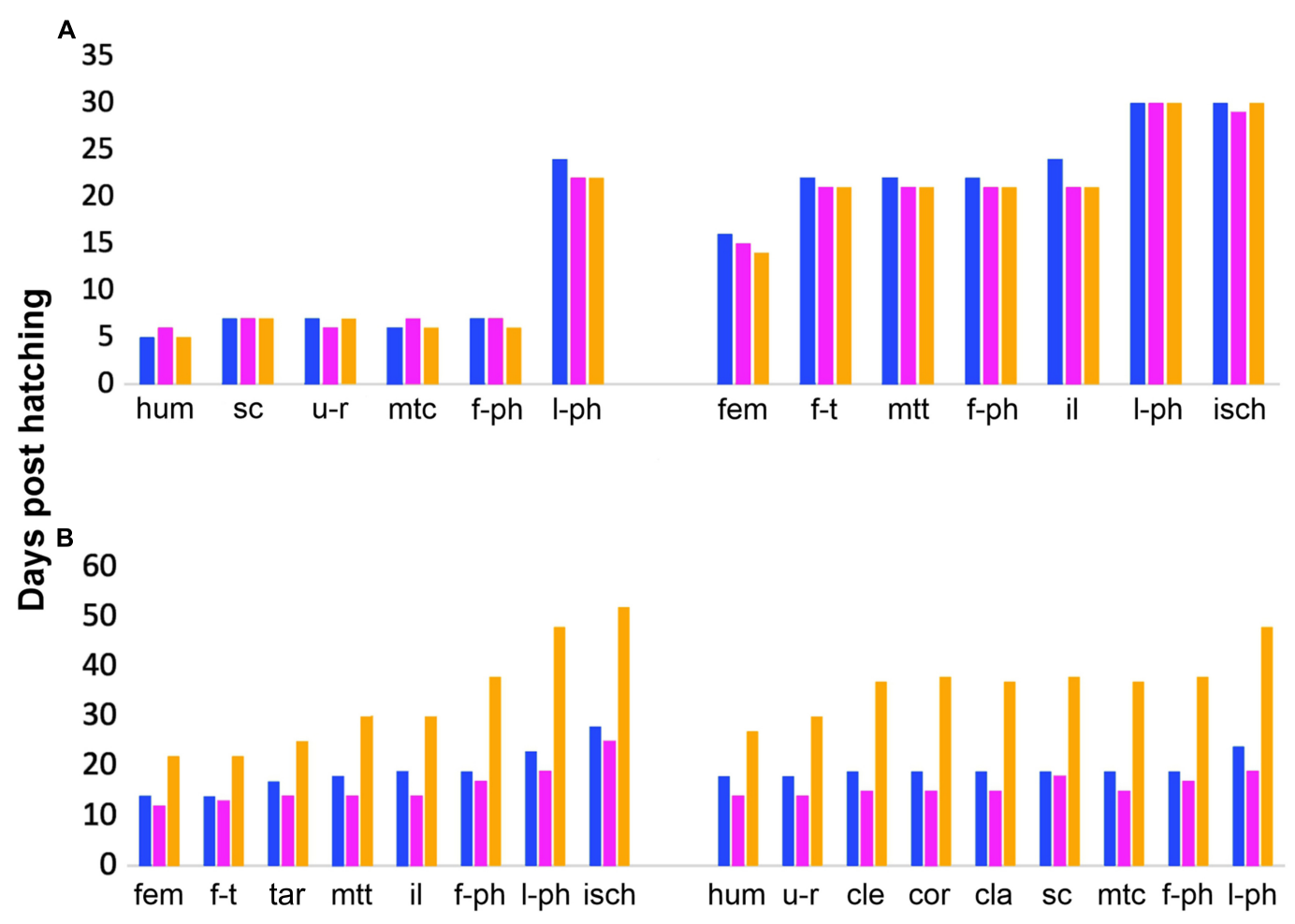

Skeletal elements

Norm $\quad \mathrm{T}_{3} 2 \times 10^{-9} \mathrm{M} \square \mathrm{TU} 0.02 \%$

FIGURE 9 | Timing of appendicular bones development (earliest appearance) under same experimental hormonal regimes (in norm, under $\mathrm{T}_{3}$ and TU-treatment), (A) in Lissotriton vulgaris (after Smirnov and Vassilieva, 2003) and (B) in Bombina variegata (this study). Abbreviations: cla, clavicle; cle, cleithrum; cor, coracoid; fem, femur; f-ph, first phalanges; f-t, fibula and tibia; tar, tarsals; hum, humerus; il, ilium; isch, ischium; I-ph, last phalanges; mtc, metacarpals; mtt, metatarsals; sc, scapula; u-r, ulna and radius.

by methimazole treatment beginning in early larval stages, the hind limbs remain bud-like in Xenopus tadpoles (Brown et al., 2005). On the other hand, in giant athyroid Xenopus tadpoles, the development of the appendicular bony skeleton is arrested at more advanced stages, and their ossification state is rather advanced relative to their length (Kerney et al., 2010). Other studies have shown that the disruption of thyroid axis at various levels allows limb cartilage to differentiate but prevents elongation (Mitsui et al., 2006; Choi et al., 2017). Our observations on $B$. variegata indicate that even under strong TH-suppression, larval limbs attain full digits differentiation and form almost all ossifications, but the longitudinal growth of the bones strictly requires increased TH-levels. On the other hand, in Pelobates fuscus (Pelobatidae), tadpoles treated with TU $0.04 \%$ hind limbs remain bud-like even after six months of the experiment (Smirnov, unpublished observations). The controversy of these data suggests that anurans can differ in the degree of TH-involvement of limb development.

\section{Axial Skeleton}

The formation of the ossified presacral and sacral vertebrae in the studied anurans appears to be only partially TH-affected.
In Xenopus laevis, they develop in naturally athyroid giant tadpoles and experimentally goitrogen-treated larvae (Kerney et al., 2010; Smirnov and Vassilieva, 2014). In B. variegata, TH-changes affect only the timing of their development (see Table 5). The posterior part of the anuran axial skeleton is formed by the urostyle, a structure that forms from the fused postsacral vertebrae (coccyx) and the ossified hypochord. This is a unique anuran feature that is thought to play a key role in the formation of the postmetamorphic anuran body plan (Handrigan and Wassersug, 2007a). A recent study showed that the development of the urostyle, especially its hypochordal part, is directly affected by THs, since in Xenopus tadpoles treated with methimazole, the formation of coccygeal vertebrae was incomplete, and the hypochord was totally absent (Senevirathne et al., 2020). However, our results show that in $B$. variegata both coccyx and hypochord are highly $\mathrm{TH}$-reactive: they markedly accelerate their development under treatment with moderate $\mathrm{T}_{3}$ dosages, but under TU-treatment with a moderate dosage, their ossification is delayed, plus the coccygeal and hypochordal parts of the urostyle remain unfused by the end of the experiment; under TU-treatment with high dosage, only primordia of the neural arches X appear, but not vertebra XI 
or hypochord. As in the appendicular skeleton, the above data indicate the possible interspecific variability in axial skeleton TH-mediation among anurans.

Our observations on $B$. variegata suggest that only a low level of THs is necessary for the development of the presacral and sacral vertebrae, whereas the urostyle beginning to form in the premetamorphic period needs a high TH-level to develop. Frogs of the Asian family Megophryidae display a striking example of necrobiotic metamorphosis in the axial skeleton. The stream-dwelling tadpoles of many megophryid genera develop caudal vertebrae (up to 30 in Leptobrachella), which disappear during metamorphosis along with tail resorption (Handrigan and Wassersug, 2007b; Handrigan et al., 2007). It is reasonable to assume that resorption of these caudal vertebrae is also $\mathrm{TH}$-inducible, as are other remodeling processes in anuran metamorphosis.

\section{Thyroid Hormone-Regulation of Amphibian Skeletal Development and Decoupling of Larval and Adult Morphology}

Earlier, experimental embryologists (Corsin, 1967; Medvedeva, 1975; Lebedkina, 1986, among others) revealed the involvement of tissue-inductive interactions in the mediation of cranial bones development in salamanders. Comparison of this non-hormonal and thyroid hormonal mediation of skull development shows that in S. keyserlingi, extirpation of the nasal sac resulted in the failure of the nasal bone to appear (Lebedkina, 1986), whereas THimpact is limited to the timing of this bone appearance (Smirnov and Vasil'eva, 2002; Smirnov et al., 2011). In salamandrids, as exemplified by Ichthyosaura alpestris, extirpation of the nasal placode did not prevent the appearance of the nasal bone but influenced its shape (Hall, 1999b, p. 147), whereas THs exerted a dominant impact on its appearance and development in L. vulgaris and P. waltl (Smirnov and Vassilieva, 2003; Smirnov et al., 2020).

Similarly, in S. keyserlingi, extirpation of the nasolacrimal duct prevented the appearance of the lacrimal bone (Medvedeva, 1975), whereas THs influenced only the timing of its appearance (Smirnov et al., 2011). In Ambystoma mexicanum, both the nasolacrimal duct and THs exerted a dominant impact on the appearance and development of the lacrimal (Medvedeva, 1986; Smirnov and Vassilieva, 2005). In salamandrids (e.g., P. waltl, Triturus karelinii, and Ishthyosaura alpestris), a separate lacrimal is absent, although it participates in the complex bone prefrontolacrimal (Medvedeva, 1975; Lebedkina, 1979, 2004; Vater, 2007). In P. waltl, the nasolacrimal duct influenced only the shape of the lacrimal portion of this bone (Medvedeva, 1975), whereas THs were necessary for its appearance (Smirnov et al., 2020). In L. vulgaris, no impact of the nasolacrimal duct was revealed (Medvedeva, 1975), whereas TH played a dominant role in this bone development (Smirnov and Vassilieva, 2003).

Septomaxilla in S. keyserlingi did not appear in the absence of the nasolacrimal duct (Medvedeva, 1975), whereas TH-changes influenced the timing of its appearance (Smirnov et al., 2011). In $A$. mexicanum, both the nasolacrimal duct and THs were necessary for the appearance of this bone (Medvedeva, 1986; Smirnov and Vassilieva, 2005). In E. bislineata, septomaxilla is $\mathrm{TH}$-inducible and appears to be independent of the nasolacrimal duct, as it may normally develop in its absence (Rose, 1995b).

These findings indicate that in the basal salamander, S. keyserlingi, inductive tissue interactions exert a dominant impact on the development of late-appearing cranial bones, whereas the role of THs is limited to influencing the timing of their appearance. In contrast, in more derived salamanders, as exemplified by A. mexicanum, L. vulgaris, P. waltl, and E. bislineata, THs induce the development of these bones, whereas non-hormonal mediation plays a minor role.

As stated by Alberch (1989), the evolution of the primarily gradual development in amphibians was accompanied by a concentration of morphological transformations on a limited ontogenetic stage, determined as metamorphosis. At the same time, experimental and histological studies on amphibians of diverse lineages by Corsin (1967), Medvedeva (1975, 1986), Lebedkina $(1979,2004)$ showed the progressive attenuation of some of inductive tissue interactions and the disintegration of inductive cascades at the transition from basal to advanced urodelans.

Although it is widely recognized that amphibian ontogeny is regulated by both non-hormonal and hormonal factors (Rose and Reiss, 1993; Hall, 1999a), it may be assumed that in salamander evolution, the decrease in the role of tissue interactions provided grounds for the enhancement of hormonal regulation and induction of skeletogenetic events. In anurans, given the THdependence of not only complete cranial development but also postcranial development, hormonal control is likely a major mechanism mediating skeletal ontogeny. The transition to hormonal control facilitates the relative independence of larval and adult cranial morphologies and, in parallel, permits the synchronization of developmental transformations. Without strong tissue interrelationships, cranial bones become released from larval constraints, and vice versa, larval elements become free from adult constraints; therefore, larval and adult morphology can be readily dissociated.

Among salamanders, this dissociation is evident in the biphasic plethodontids, which display the maximum $\mathrm{TH}$ involvement in the mediation of skull development. In contrast, both TH-involvement and developmental differences in cranial morphology are relatively slight in hynobiids (Smirnov, 2006).

In anurans, whose skeletal development is mainly mediated by THs, the difference is enormous if skulls are compared between tadpoles and frogs. Moreover, anuran larvae display a wide range of cranial morphologies due to the acquisition of numerous larval-specific features adaptive to a variety of trophic specializations, such as suspension-feeding, detritophagy or predation (Haas and Richards, 1998; Haas, 2003; Vera Candioti, 2007, to name a few).

In caecilians, the third lineage of extant amphibians, cranial development is a gradual process, as exemplified by the basal Epicrionops sp. (Reiss, 1996). In this apodan, the adult skull differs from the late larval skull, mainly in the "increase in the area of dermal bones" (Rose and Reiss, 1993, p. 303). The only evident metamorphic event is the fusion of the maxilla and palatine 
accompanied by the division of the pterygoid into two portions, although the latter is an individually variable feature not shared by other caecilians (Reiss, 1996).

A gradual pattern of cranial development with only a few slight differences in larval and adult morphologies is revealed in the putative ancestors of recent amphibians, dissorophoid temnospondyls, for whom detailed ontogenetic series are known (Schoch, 1998, 2002; Boy and Sues, 2000). Thus, in Apateon gracilis (Branchiosauridae), all cranial bones appeared during the larval period, and the palate did not undergo metamorphic rearrangement (Schoch and Fröbisch, 2006). However, both caecilians and branchiosaurids display profound metamorphic transformation of the hyobranchium (Boy and Sues, 2000; Wake, 2003).

Given the revealed correlation between the level of THinvolvement and the degree of larval/adult cranial dissociation in frogs and salamanders, THs seem to play a minor (if ever) role in the mediation of skull development in both apodans and temnospondyls.

The transition to hormonal mediation enhances the independence of larval and adult developmental programmes, thus creating preconditions for necrobiotic metamorphosis. Usually, within amphibians, necrobiotic metamorphosis is considered a characteristic of anurans, which undergo drastic metamorphic changes in the body plan. In anurans, larval specializations (e.g., the suprarostral cartilages and trabecular horns in the skull and tail in the locomotory system) resorb during the larval-adult transition rather than rearrange into adult ones. Although in urodelans, the body plan does not change fundamentally during larval-adult transformation, the latter also includes necrobiotic processes, as exemplified by the resorption of provisory bones (coronoid, palatine, larval vomer, and their dentitions). By repeated vital staining, Lebedkina $(1979,2004)$ showed that larval vomer in salamanders does not rearrange into adult bone but resorbs completely and becomes replaced by adult vomer differing in the microstructure of bony tissue. The remodeling of the larval hyobranchium in metamorphosing urodelans also implies the resorption of some cartilaginous elements of the hyobranchium and the transformation of others (Rose, 2003). However, in the plethodontid Eurycea bislineata, adult ceratobranchial cartilage was shown to develop de novo rather than rearranged (Alberch and Gale, 1986). All these necrobiotic events in both frogs and salamanders are strictly TH-dependent.

\section{The Increasing Role of Thyroid Hormones in the Regulation of Amphibian Development: Implications for Life History Evolution}

We hypothesize that THs play a key role in the major evolutionary repatterning of amphibian ontogeny and life history.

\section{Direct Development}

The transition to hormonal control of the adult portion of the skeletal developmental programme allows larval and adult cranial morphologies to be readily dissociated as exemplified by direct-developing and neotenic salamanders lacking larval and adult skull morphology, respectively. Given the strong TH-impact on cranial development revealed in the salamanders of the family Plethodontidae by Rose (1995a,b), it is no wonder that this salamander lineage demonstrates the largest diversity of cranial developmental patterns. Some plethodontids, e.g., Eurycea bislineata studied in detail by Rose (1995a,b,c), are biphasic and display both larval and adult skull morphology. Several species are neotenic (the so-called perennibranchiates) and lack adult cranial morphology. Most plethodontids are direct-developers and lack larval skull morphology. Whereas questions such as whether direct development is primitive or derived in plethodontids and how many times it has arisen are widely discussed (Chippindale et al., 2004; Mueller et al., 2004; Bonett et al., 2005, 2014; Beachy et al., 2017), knowledge on the skeletal development of direct-developers is fragmentary (Alberch and Alberch, 1981; Hanken, 1984; Ehmcke and Clemen, 2000; Dulcey Cala et al., 2009). To date, in most detail, the cranial ontogeny of a direct-developing salamander has been described by Marks (2000) in Desmognathus aeneus. In this salamander, in contrast to biphasic plethodontids, the usual sequence of bone appearance is altered (e.g., the maxilla appears precociously), larval bones, palatopterygoid and coronoid, do not appear, and larval vomer is greatly underdeveloped, whereas the adult vomerine portion appears precociously and precedes the appearance of several bones, including the nasal and septomaxilla.

Although direct development has been hypothesized to involve a shift toward precocious activation of the thyroid gland (Lynn, 1961; Matsuda, 1987), little evidence of TH-dependence in direct-developing embryos of plethodontids has been found (Dent, 1942). Under these circumstances, it is worth noting that the pattern of cranial development recorded in D. aeneus is remarkably similar to that observed in the TH-treated early larvae of $L$. vulgaris. In this newt, TH-treatment, which mimics the precocious natural TH-peak, resulted in the precocious appearance of the maxilla and posterior (adult) portion of the vomer. Both appeared when larval vomer, coronoid, and palatopterygoid remained underdeveloped and one-third of cranial bones were still absent (Smirnov and Vassilieva, 2003).

Although this evidence provides only indirect support for the hypothesis that direct development in plethodontids evolved via precocious $\mathrm{TH}$-activity, the similarity of cranial development in $D$. aeneus to that observed in TH-treated $L$. vulgaris larvae seems rather prospective.

Among anurans, direct development is widespread and has arisen independently multiple times in a wide variety of families (Duellman and Trueb, 1986; Gomez-Mestre et al., 2012; Bardua et al., 2021). Most knowledge on directdeveloping frogs comes from studies of Eleutherodactylus coqui (Eleutherodactylidae). Skeletal development of this frog displays profound ontogenetic repatterning: (i) larval-specific features such as the suprarostral cartilage and trabecular horns never form; (ii) Meckel's, infrarostral, and palatoquadrate cartilages, as well as the hyobranchium since their appearance resemble a mid-metamorphic stage of development in metamorphosing 
anurans; and (iii) the skull ossification sequence is unusual in that bones associated with the suspensorium (squamosal) and jaws (angulosplenial, premaxilla, dentary, and maxilla) appear precociously (Hanken et al., 1992).

Initially, this ontogenetic repatterning was hypothesized to occur due to the emancipation of developmental processes from TH-dependence (Hanken et al., 1997). However, further experimental studies have shown that E. coqui undergoes ontogenetic transformation, "cryptic metamorphosis," which closely resembles the metamorphosis of biphasic frogs and is largely orchestrated by THs (Jennings and Hanken, 1998; Callery and Elinson, 2000).

The thyroid activity and $\mathrm{TH}$ profile in E. coqui display the same pattern as in biphasic anurans: their significant rise coincides with the phase of the most significant morphological rearrangements and is followed by a decline (Hanken et al., 1992; Laslo et al., 2019). The main difference is that in E. coqui, the TH-rise occurs in an embryo.

There is little research on skeletal ontogeny in directdeveloping frogs other than E. coqui. Those that were studied display different degrees of ontogenetic repatterning, which is less pronounced than in E. coqui, but all of them exhibit precocious appearance of at least some bones associated with the suspensorium and jaws, as found in some Neotropical frogs of the families Craugastoridae and Brachycephalidae (Vera Candioti et al., 2020), as well as in Asian tree frogs (Rhacophoridae) (Kerney et al., 2007; Vassilieva, 2017). A similar trend was also revealed in Eleutherodactylus guentheri (Lynn and Lutz, 1946), E. nubicola (Lynn, 1942), and E. ricordii (Hughes, 1959).

Remarkably, a similar sequence change, i.e., the precocious appearance of bones, which contribute to the upper and lower jaws and suspensorium, is observed in a biphasic anuran, $B$. variegata, under experimental treatment with high $\mathrm{TH}$-dosages (this study) (Figure 10). Previously, the ontogenetic cranial pattern in TH-treated early newt larvae was revealed to resemble closely that of the direct-developing salamander (see above).The similarity of these phenomena (likeness of the direct-developer and TH-treated biphasic amphibian) in salamanders and frogs seems more than mere coincidence. Rather, it seems to support the hypothesis that direct development in anurans and urodelans evolved via precocious $\mathrm{TH}$-activity.

\section{Paedomorphosis}

In urodelans with their decoupled somatic and reproductive development, heterochronies leading to paedomorphic underdevelopment are widespread: neotenic forms (i.e., larval reproducers) are found in most recent families of Caudata. The development of the skeleton, in particular the skull, in paedomorphic urodelans shows signs of arrest at different stages, ranging from mid-larval to almost metamorphic. Paedomorphic signs are displayed in the loss of a more or less extensive set of cranial bones, as well as in the retention of the provisory larval bones (coronoid and palatine) and in the incomplete (if ever) remodeling of the larval palate. Five families (Plethodontidae, Cryptobranchidae, Sirenidae, Proteidae, and Amphiumidae) contain obligate neotenics. The last four are represented exclusively by neotenic species.
Neotenic (perennibranchiate) plethodontids lack lateappearing bones (e.g., maxilla and septomaxilla) and retain larval vomer, palatopterygoid, and coronoid (Rose, 1999, 2003). This cranial underdevelopment seems to result from thyroid dysfunction since TH-treatment induced resorption of the coronoid in Eurycea wallacei (Dundee, 1962) and the appearance of the maxilla and septomaxilla in Eurycea rathbuni (Dundee, 1957). It is worth noting that these two salamanders are obligate neotenics, whereas other perennibranchiate plethodontids retain the capacity to metamorphose and naturally metamorphosed individuals are occasionally found, e.g., Gyrinophilus palleucus according to Yeatman and Miller (1985) and Eurycea tynerensis (Bonett et al., 2014).

Dysfunction of the thyroid axis has also been proposed (Rose, $1996,1999,2003)$ to be responsible for the underdevelopment of the skull in the obligate neotenic salamanders Andrias japonicus, A. davidianus and Cryptobranchus alleganiensis (Cryptobranchidae); Siren intermedia, S. lacertina, and Pseudobranchus striatus (Sirenidae); and Necturus maculosus and Proteus anguinus (Proteidae), which display skull morphology ranging from almost completely adult in cryptobranchids to mostly larval in proteids (Larsen, 1963; Reilly and Altig, 1996; Rose, 2003). Although TH-synthesis dysfunction seems possible, all attempts to induce cranial transformation via TH-treatment were unsuccessful, but Safi et al. (1997a,b) proposed other mechanisms of the disruption of thyroid axis function in proteids. Consequently, other reasons for cranial underdevelopment are not excluded. In the basal A. japonicus, which undergoes metamorphic skull remodeling with the resorption of the palatine and coronoid, late-appearing bones such as the septomaxilla and lacrimal fail to arise (Rose, 2003). It is these bones that in the basal cryptobranchoid salamanders, S. keyserlingii and Ranodon sibiricus (Hynobiidae), are obligately induced by the nasolacrimal duct and do not develop in its absence (Medvedeva, 1975). Since cryptobranchids lack the nasolacrimal duct, it seems highly likely that its absence prevents the development of these bones rather than some hormonal factor.

Paedomorphic skeletal modifications are also widely distributed among anurans, although skeletal underdevelopment is less pronounced in them. In frogs, sexual development is strictly TH-dependent, and reproduction is impossible in animals that do not metamorphose (Hayes, 1997). Although ovary maturation was observed in giant athyroid Xenopus tadpoles (Rot-Nikcevic and Wassersug, 2004) and in longliving overwintering Pelobates fuscus tadpoles (Smirnov, 1992), anuran larval reproducers have never been found. Therefore, the dependence of anuran development upon THs prevents the evolution of neoteny. Since frogs need metamorphosis to reproduce, arrest of development at stages preceding the metamorphic climax is impossible. In parallel, loss of highly TH-mediated bones associated with metamorphosis is also impossible. Bones that are subjected to paedomorphic loss or underdevelopment are among the last-appearing bones. They arise after the $\mathrm{TH}$-peak and, as exemplified by B. variegata (this study), seem to be less TH-controlled. Usually, quadratojugal, palatine, and stapes, and sometimes vomer and sphenethmoid 


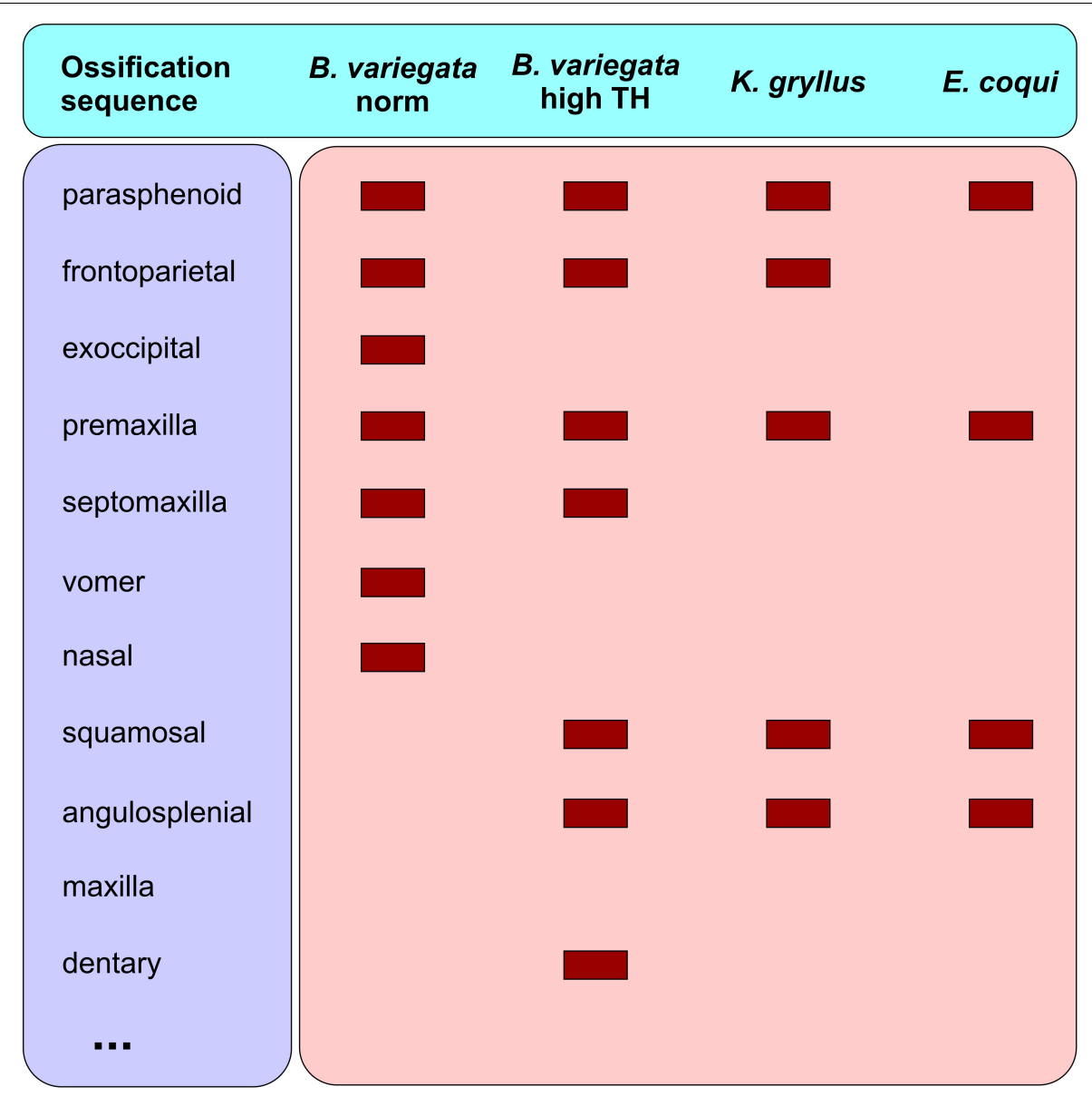

FIGURE 10 | First cranial bones in Bombina variegata (under normal conditions and under high-dosage $T_{3}$-treatment beginning from 6 dph) and in direct developing frogs, Kurixalus gryllus (after Vassilieva, 2017) and Eleutherodactylus coqui (after Hanken et al., 1992).

are lost in paedomorphic frogs (Davies, 1989; Yeh, 2002). It is these bones that usually arise last in the cranial ossification sequence (Weisbecker and Mitgutsch, 2010).

\section{THYROID HORMONES AND SKELETOGENESIS IN AMPHIBIANS: CONCLUDING REMARKS AND PERSPECTIVES}

A number of studies, including this review, show that THchanges, artificially caused in developing salamanders, result in skeletal changes. A similar phenomenon is displayed by naturally developing urodeles. The most profound evidence of $\mathrm{TH}$-involvement in the diversification of skeletal morphology in salamanders is shown by neotenic species. Facultative neoteny, a common event among salamanders, results from thyroid axis dysfunction, as proven by artificially induced metamorphosis in $\mathrm{TH}$-treated neotenics.

Facultative neotenics do not complete metamorphosis and, as adults, retain larval features in the skull and hyobranchial apparatus. The neotenic individuals of Batrachuperus londongensis (Hynobiidae) display an incomplete resorption of palatine and retain extra ceratobranchials in the hyobranchium (Jiang et al., 2018). In the neotenic Dicamptodon tenebrosus (Dicamptodontidae), cranial development arrests at a mid to late larval stage: the vomer and palatopterygoid are larval, a rudimentary toothless coronoid is retained, the nasal is absent and the septomaxilla is variably present (Rose, 2003). In the ambystomatid salamander, Ambystoma talpoideum, neotenic individuals completely retain larval hyobranchium, although their palatopterygoid may disintegrate (Reilly, 1987). Among Salamandridae, neotenic (paedotypic) individuals of Lissotriton vulgaris and Ichthyosaura alpestris usually retain a complete or only partially resorbed palatopterygoid in parallel with the larval vomer and hyobranchium. Additionally, sometimes they lack the nasal and prefrontal (Djorović and Kalezić, 2000; Ivanović et al., 2014). Neotenic Notophthalmus viridiscens newts display the occurrence of a completely adult skull accompanied by a hyobranchium differing in the degree of transformation. The latter may (i) retain the completely larval morphology (but with ossified primarily cartilaginous elements), (ii) attain almost complete metamorphic remodeling, or (iii) show an intermediate morphology (Reilly, 1987). Neotenic plethodontids 
display the most underdeveloped morphology: they lack the maxilla, nasal, prefrontal, and septomaxilla and retain the larval vomer, palatopterygoid, and coronoid (Rose, 2003). In normal, biphasic development, the appearance of these lacking bones and remodeling of the palate and hyobranchium are associated with the metamorphic climax and are TH-inducible.

Since no larval reproducers are known among anurans, THinvolvement in the diversification of anuran larval development as well as of adult morphology is much less evident than in urodeles. Our study has shown that changes in thyroid function (i) influence the rate and length of larval development, (ii) cause changes in the ossification sequence, (iii) provoke changes in the pattern of bone formation, (iv) induce the appearance of additional centers of ossification, (v) facilitate bones fusion, and (vi) may result in their underdevelopment or loss. Consequently, the occurrence of such events in the developing frog may suggest the occurrence of changes in thyroid axis function.

For example, Pseudys platensis (Hylidae) has a very prolonged larval development several months long (Downie et al., 2009; Fabrezi et al., 2009) and is uncommon for the studied anuran developmental events: this frog completes the cranial ossification sequence and differentiation of the plectral apparatus of the middle ear prior to the end of metamorphosis (Fabrezi and Goldberg, 2009). This precocious skeletal formation suggests a precocious increase in TH-level. This seems to be the case since the profile of thyroid gland activity in P. platensis larvae rises in the prometamorphic phase, i.e., well before the metamorphic climax (Cruz and Fabrezi, 2020).

In contrast, frogs of Lepidobatrachus species (Ceratophryidae) are characterized by larval development shortened to less than three weeks (Ruibal and Thomas, 1988; Fabrezi, 2011). Predatory tadpoles of Lepidobatrachus are distinguished by a mixture of larval, mid-metamorphic, and adult features, including skeleton (Ruibal and Thomas, 1988; Hanken, 1993; Fabrezi and Quinzio, 2008). The peculiarities of Lepidobatrachus morphology were explained by "premature metamorphosis" (Hanken, 1993), which was suggested to result from an early rise in TH-level (Fabrezi and Cruz, 2014). However, since histological examination did not reveal any distinctive peak in thyroid gland activity in Lepidobatrachus tadpoles, it was hypothesized that the $\mathrm{TH}$ increase was attained due to maternal THs or live prey (Fabrezi and Cruz, 2014).

In adult anurans, variability in the relative lengths of hind limbs in two species of the Telmatobius genus (Telmatobiidae) was proposed to result from environmentally (via temperature) caused differences in the reaction to TH-influence (Barrionuevo, 2020).

Morphological changes artificially caused by TH-changes in B. variegata (this study) are similar to those usually found in naturally developing amphibians. However, this similarity does not automatically indicate the latter to result from changes in thyroid physiology. TH-involvement remains hypothetical until the experimental test. In our study, $\mathrm{TH}$-involvement, degree of $\mathrm{TH}$-influence, level of $\mathrm{TH}$-sensitivity, morphological consequences of $\mathrm{TH}$-changes and their dependence upon the timing and dosage of $\mathrm{TH}$ - or $\mathrm{TU}$-administration, among others, were evaluated with a combination of artificially induced THdeficiency and TH-treatment. Variable parameters in this study were $\mathrm{TH}$ and $\mathrm{TU}$ concentrations, timing of their administration and stage of animal development. Additionally, salamanders previously studied using the same experimental protocol differ in their phylogenetic position from basal in $S$. keyserlingi (Hynobiidae) to more derived in P. walt and L. vulgaris (Salamandridae).

Thyroid hormones are intensively studied, and new experimental methods will doubtless appear, but the experimental approach used in our study seems adequate for assigned targets and may be applied in future research. Such research will benefit if it (i) is not limited to model species (e.g., Xenopus and Pleurodeles) but includes various species differing in phylogenetic position, life cycle, developmental trajectory, and ecological adaptations; (ii) studies both bones and cartilages and the interplay between them; and (iii) uses in parallel different agents influencing different processes in the thyroid pathway. The last point is important since deviation in any process included in the thyroid pathway may influence thyroid physiology and cause consequent changes in development and morphology. It is worth noting that differences in the morphology of metamorphosing and neotenic plethodontid Eurycea tynerensis salamanders were recently revealed to result from differences in the transcriptional activity of thyroid hormone receptors (Aran et al., 2014).

\section{DATA AVAILABILITY STATEMENT}

The raw data supporting the conclusions of this article will be made available by the authors, without undue reservation.

\section{ETHICS STATEMENT}

The animal study was reviewed and approved by the Severtsov Institute's Animal Ethics Committee.

\section{AUTHOR CONTRIBUTIONS}

AV performed the experiment, obtained and analyzed the data, made the photographs, prepared the figures and tables, conceptualized the hypothesis, reviewed the literature, and wrote the manuscript. SS planned and designed the study, analyzed the data, conceptualized the hypothesis, discussed the results, reviewed the literature, and wrote and edited the manuscript. Both authors approved the final version of the manuscript.

\section{ACKNOWLEDGMENTS}

The authors are deeply indebted to Irina Serbinova from the Moscow Zoo for breeding Bombina variegata, to Vitaly Trounov for technical assistance and to Alexey Tsessarsky and Fedor Shkil for their kind help with microphotography. 


\section{REFERENCES}

Ajduković, M., Vučić, T., and Cvijanović, M. (2021). Effect of thiourea on the skull of Triturus newts during ontogeny. PeerJ 9:e11535. doi: 10.7717/peerj.11535

Alberch, P. (1989). "Development and the evolution of amphibian metamorphosis," in Trends in Vertebrate Morphology (Fortschritte der Zoologie), eds H. Splechtna and H. Hilgers (Stuttgart: Gustav Fischer Verlag), 163-173.

Alberch, P., and Alberch, J. (1981). Heterochronic mechanisms of morphological diversification and evolutionary change in the neotropical salamander, Bolitoglossa occidentalis (Amphibia: Plethodontidae). J. Morphol. 167, 249-264. doi: $10.1002 /$ jmor. 1051670208

Alberch, P., and Gale, E. A. (1986). Pathways of cytodifferentiation during the metamorphosis of the epibranchial cartilage in the salamander Eurycea bislineata. Dev. Biol. 117, 233-244. doi: 10.1016/0012-1606(86)90366-0

Alberch, P., Gale, E. A., and Larsen, P. R. (1986). Plasma T4 and T3 levels in naturally metamorphosing Eurycea bislineata (Amphibia; Plethodontidae). Gen. Comp. Endocrinol. 61, 153-163. doi: 10.1016/0016-6480(86)90261-3

Aran, R. P., Steffen, M. A., Martin, S. D., Lopez, O. I., and Bonett, R. M. (2014), Reduced effects of thyroid hormone on gene expression and metamorphosis in a paedomorphic plethodontid salamander. J. Exp. Zool. B. Mol. Dev. Evol. 322B, 294-303. doi: 10.1002/jez.b.22580

Banbury, B., and Maglia, A. M. (2006). Skeletal development of the Mexican spadefoot, Spea multiplicata (Anura: Pelobatidae). J. Morphol. 267, 803-821. doi: 10.1002/jmor.10441

Bardua, C., Fabre, A. C., Clavel, J., Bon, M., Das, K., Stanley, E. L., et al. (2021). Size, microhabitat, and loss of larval feeding drive cranial diversification in frogs. Nat. Commun. 12:2503. doi: 10.1038/s41467-021-22792-y

Barrionuevo, J. S. (2020). Variation in the growth and development of the hind limbs in frogs of the genus Telmatobius (Anura: Telmatobiidae). J. Morphol. 281, 1534-1546. doi: 10.1002/jmor.21264

Beachy, C. K., Ryan, T. J., and Bonett, R. M. (2017). How metamorphosis is different in plethodontids: larval life history perspectives on life-cycle evolution. Herpetologica 73, 252-258. doi: 10.1655/herpetologica-d-16-00083.1

Bonett, R. M., Mueller, R. L., and Wake, D. B. (2005). Why should reacquisition of larval stages by desmognathine salamanders surprise us? Herpetol. Rev. 36, 112-113.

Bonett, R. M., Steffen, M. A., Lambert, S. M., Wiens, J. J., and Chippindale, P. T. (2014). Evolution of paedomorphosis in plethodontid salamanders: ecological correlates and re-evolution of metamorphosis. Evolution 68, 466-482. doi: $10.1111 /$ evo.12274

Boy, J. A., and Sues, H.-D. (2000). "Branchiosaurs: larvae, metamorphosis and heterochrony in temnospondyls and seymouriamorphs," in Amphibian Biology. Palaeontology, Vol. 4, eds H. Heatwole and R. L. Carroll (Chipping Norton: Surrey Beatty \& Sons), 1150-1197.

Brown, D. D. (1997). The role of thyroid hormone in zebrafish and axolotl development. Proc. Natl. Acad. Sci. U.S.A. 94, 13011-13016. doi: 10.1073/pnas. 94.24.13011

Brown, D. D., and Cai, L. (2007). Amphibian metamorphosis. Dev. Biol. 306, 20-33.

Brown, D. D., Cai, L., Das, B., Marsh-Armstrong, N., Schreiber, A. M., and Juste, R. (2005). Thyroid hormone controls multiple independent programs required for limb development in Xenopus laevis metamorphosis. Proc. Natl. Acad. Sci. U.S.A. 102, 12455-12458. doi: 10.1073/pnas.0505989102

Callery, E. M., and Elinson, R. P. (2000). Thyroid hormone-dependent metamorphosis in a direct developing frog. Proc. Natl. Acad. Sci. U.S.A. 97, 2615-2620. doi: 10.1073/pnas.050501097

Chippindale, P. T., Bonett, R. M., Baldwin, A. S., and Wiens, J. J. (2004). Phylogenetic evidence for a major reversal of life history evolution in plethodontid salamanders. Evolution 58, 2809-2822. doi: 10.1111/j.0014-3820. 2004.tb01632.x

Choi, J., Ishizuya-Oka, A., and Buchholz, D. R. (2017). Growth, development, and intestinal remodeling occurs in the absence of thyroid hormone receptor $\alpha$ in tadpoles of Xenopus tropicalis. Endocrinology 158, 1623-1633. doi: 10.1210/en. 2016- 1955

Čihák, R., Královec, K., and Roček, Z. (2003). Developmental origin of the frontoparietal bone in Bombina variegata (Anura: Discoglossidae). J. Morphol. 255, 122-129. doi: 10.1002/jmor.10055
Clemen, G., and Greven, H. (2018). Long-term effects of arrested metamorphosis on dental systems in Salamandra salamandra (Salamandridae: Urodela). Vert. Zool. 68, 143-155.

Corsin, J. (1967). "Quelques problèmes de morphogenèse du crâne chez les urodèles," in problèmes actuels de paléontologie (evolution des vertébrés). Coll. Int. Cent. Nat. Rec. Scient. 163, 295-299.

Cruz, J. C., and Fabrezi, M. (2020). Histology and microscopic anatomy of the thyroid gland during the larval development of Pseudis platensis (Anura, Hylidae). J. Morphol. 281, 122-134. doi: 10.1002/jmor.21085

Davies, M. (1989). Ontogeny of bone and the role of heterochrony in the myobatrachine genera Uperoleia, Crinia, and Pseudophryne (Anura: Leptodactylidae: Myobatrachinae). J. Morphol. 200, 269-300. doi: 10.1002/ jmor.1052000305

Dent, J. N. (1942). The embryonic development of Plethodon cinereus as correlated with the differentiation and functioning of the thyroid gland. J. Morphol. 71, 577-601. doi: 10.1002/jmor.1050710307

Djorović, A., and Kalezić, M. L. (2000). Paedogenesis in European newts (Triturus: Salamandridae): cranial morphology during ontogeny. J. Morphol. 243, 127139. doi: 10.1002/(sici) 1097-4687(200002)243:2<127::aid-jmor2>3.0.co;2-0

Downie, J. R., Ramnarine, I., Sams, K., and Walsh, P. T. (2009). The paradoxical frog Pseudys paradoxa: larval habitat, growth and metamorphosis. Herpetol. J. $19,11-19$.

Duellman, W. E., and Trueb, L. (1986). Biology of Amphibians. New York, NY: McGraw-Hill.

Dulcey Cala, C. J., Tarazona, O. A., and Ramírez-Pinilla, M. P. (2009). The morphology and post-hatching development of the skull of Bolitoglossa nicefori (Caudata: Plethodontidae): developmental implications of recapitulation and repatterning. Zoology 112, 227-239. doi: 10.1016/j.zool.2008.09.006

Dundee, H. A. (1957). Partial metamorphosis induced in Typhlomolge rathbuni. Copeia 1957, 52-53. doi: 10.2307/1440522

Dundee, H. A. (1962). Response of the neotenic salamander Haideotriton wallacei to a metamorphic agent. Science 135, 1060-1061. doi: 10.1126/science.135. 3508.1060

Eagleson, G. W., and McKeown, B. A. (1978). Changes in thyroid activity of Ambystoma gracile (Baird) during different larval, transforming, and postmetamorphic phases. Can. J. Zool. 56, 1377-1381. doi: 10.1139/z78-190

Ehmcke, J., and Clemen, G. (2000). The structure and development of the skull of costa rican plethodontid salamanders (Amphibia: Urodela). Anna. Anat. 182, 537-547. doi: 10.1016/s0940-9602(00)80100-4

Fabrezi, M. (2011). Heterochrony in growth and development in anurans from the Chaco of South America. Evol. Biol. 38, 390-411. doi: 10.1007/s11692-0119128-5

Fabrezi, M., and Cruz, J. C. (2014). Ontogeny of the thyroid glands during larval development of South American horned frogs (Anura, Ceratophryidae). Evol. Biol. 41, 606-618. doi: 10.1007/s11692-014-9292-5

Fabrezi, M., and Goldberg, J. (2009). Heterochrony during skeletal development of Pseudis platensis (Anura, Hylidae) and the early offset of skeleton development and growth. J. Morphol. 270, 205-220. doi: 10.1002/jmor.10680

Fabrezi, M., and Quinzio, S. I. (2008). Morphological evolution in Ceratophryinae frogs (Anura, Neobatrachia): the effects of heterochronic changes during larval development and metamorphosis. Zool. J. Linnean Soc. 154, 752-780. doi: 10.1111/j.1096-3642.2008.00420.x

Fabrezi, M., Lozano, V. L., and Cruz, J. C. (2019). Differences in responsiveness and sensitivity to exogenous disruptors of the thyroid gland in three anuran species. J. Exp. Zool. Part B. 332, 279-293. doi: 10.1002/jez.b.22908

Fabrezi, M., Quinzio, S. I., and Goldberg, J. (2009). Giant tadpole and delayed metamorphosis of Pseudis platensis Gallardo, 1961 (Anura, Hylidae). J. Herpetol. 43, 228-243. doi: 10.1670/08-028r3.1

Fort, D. J., Degitz, S., Tietge, J., and Touart, L. W. (2007). The hypothalamicpituitary-thyroid (HPT) axis in frogs and its role in frog development and reproduction. Cri. Rev. Toxicol. 37, 117-161. doi: 10.1080/10408440601123545

Fritzsch, B. (1990). The evolution of metamorphosis in amphibians. J. Neurobiol. 21, 1011-1021. doi: 10.1002/neu.480210707

Frost, D. R. (2021). Amphibian Species of the World: an Online Reference. Version 6.1. New York, NY: American Museum of Natural History.

Furlow, J. D., and Neff, E. S. (2006). A developmental switch induced by thyroid hormone: Xenopus laevis metamorphosis. Trends Endocrinol. Metab. 17, 40-47. doi: 10.1016/j.tem.2006.01.007 
Galton, V. A. (1992). The role of thyroid hormone in amphibian metamorphosis. Trends Endocrinol. Metab. 3, 96-100. doi: 10.1016/1043-2760(92)90020-2

Gomez-Mestre, I., Pyron, R. A., and Wiens, J. J. (2012). Phylogenetic analyses reveal unexpected patterns in the evolution of reproductive modes in frogs. Evolution 66, 3687-3700. doi: 10.1111/j.1558-5646.2012.01715.x

Gosner, K. L. (1960). A simplified table for staging anuran embryos and larvae. Herpetologica 16, 183-190.

Grimaldi, A., Buisine, N., Miller, T., Shi, Y.-B., and Sachs, L. M. (2013). Mechanisms of thyroid hormone receptor action during development: lessons from amphibian studies. Biochim. Biophys. Acta 1830, 3882-3892. doi: 10.1016/ j.bbagen.2012.04.020

Haas, A. (2003). Phylogeny of frogs as inferred from primarily larval characters (Amphibia: Anura). Cladistics 19, 23-89. doi: 10.1016/s0748-3007(03)00006-9

Haas, A., and Richards, S. J. (1998). Correlations of cranial morphology, ecology, and evolution in Australian suctorial tadpoles of the genera Litoria and Nyctimystes (Amphibia: Anura: Hylidae: Pelodryadinae). J. Morphol. 238, 109141. doi: 10.1002/(sici)1097-4687(199811)238:2<109::aid-jmor1>3.0.co;2-\#

Hall, B. K. (1999a). Evolutionary Developmental Biology. Dordrecht: Springer.

Hall, B. K. (1999b). The Neural Crest in Development and Evolution. New York, NY: Springer-Verlag, Inc.

Hall, J. A., and Larsen, J. H. Jr. (1998). Postembryonic ontogeny of the spadefoot toad, Scaphiopus intermontanus (Anura: Pelobatidae): skeletal morphology. J. Morphol. 238, 179-244. doi: 10.1002/(sici)1097-4687(199811)238:2<179:: aid-jmor4 $>3.0 . c 0 ; 2-6$

Handrigan, G. R., and Wassersug, R. J. (2007a). The anuran Bauplan: a review of the adaptive, developmental, and genetic underpinnings of frog and tadpole morphology. Biol. Rev. 82, 1-25. doi: 10.1111/j.1469-185x.2006.00001.x

Handrigan, G. R., and Wassersug, R. J. (2007b). The metamorphic fate of supernumerary caudal vertebrae in South Asian litter frogs (Anura: Megophryidae). J. Anat. 211, 271-279. doi: 10.1111/j.1469-7580.2007.00757.x

Handrigan, G. R., Haas, A., and Wassersug, R. J. (2007). Bony-tailed tadpoles: the development of supernumerary caudal vertebrae in larval megophryids (Anura). Evol. Dev. 9, 190-202. doi: 10.1111/j.1525-142x.2007.00149.x

Hanken, J. (1984). Miniaturization and its effects on cranial morphology in plethodontid salamanders, genus Thorius (Amphibia: Plethodontidae). I. osteological variation. Biol. J. Linn. Soc. Lond. 23, 55-75. doi: 10.1111/j.10958312.1984.tb00806.x

Hanken, J. (1993). Model systems versus outgroups: alternative approaches to the study of head development and evolution. Am. Zool. 33, 448-456. doi: $10.1093 / \mathrm{icb} / 33.4 .448$

Hanken, J., and Hall, B. K. (1984). Variation and timing of the cranial ossification sequence of the oriental fire-bellied toad, Bombina orientalis (Amphibia, Discoglossidae). J. Morphol. 182, 245-255. doi: 10.1002/jmor.1051820302

Hanken, J., and Hall, B. K. (1988a). Skull development during anuran metamorphosis: I. Early development of the first three bones to form-the exoccipital, the parasphenoid, and the frontoparietal. J. Morphol. 195, 247-256. doi: $10.1002 /$ jmor. 1051950303

Hanken, J., and Hall, B. K. (1988b). Skull development during anuran metamorphosis. II. Role of thyroid hormone in osteogenesis. Anat. Embryol. 178, 219-227. doi: 10.1007/bf00318225

Hanken, J., and Summers, C. H. (1988). Skull development during anuran metamorphosis: III. Role of thyroid hormone in chondrogenesis. J. Exp. Zool. 246, 156-170. doi: 10.1002/jez.1402460208

Hanken, J., Jennings, D. H., and Olsson, L. (1997). Mechanistic basis of life-history evolution in anuran amphibians: direct development. Am. Zool. 37, 160-171. doi: $10.1093 / \mathrm{icb} / 37.2 .160$

Hanken, J., Klymkowsky, M. W., Summers, C. H., Seufert, D. W., and Ingebrigtsen, N. (1992). Cranial ontogeny in the direct-developing frog, Eleutherodactylus coqui (Anura: Leptodactylidae), analyzed using wholemount immunohistochemistry. J. Morphol. 211, 95-118. doi: 10.1002/jmor. 1052110111

Hayes, T. B. (1997). Hormonal mechanisms as potential constraints on evolution: examples from the Anura. Am. Zool. 37, 482-490. doi: 10.1093/icb/37.6.482

Hughes, A. (1959). Studies in embryonic and larval development in Amphibia. I. The embryology of Eleutherodactylus ricordii, with special reference to the spinal cord. J. Emhryol. Exp. Morphol 7, 22-38.

Ivanović, A., Cvijanović, M., Denoël, M., Slijepčević, M., and Kalezić, M. L. (2014). Facultative paedomorphosis and the pattern of intra-and interspecific variation in cranial skeleton: lessons from European newts (Ichthyosaura alpestris and Lissotriton vulgaris). Zoomorphology 133, 99-109. doi: 10.1007/s00435-0130202-7

Jennings, D. H., and Hanken, J. (1998). Mechanistic basis of life history evolution in anuran amphibians: thyroid gland development in the direct-developing frog, Eleutherodactylus coqui. Gen. Comp. Endocrinol. 111, 225-232. doi: 10.1006/ gcen.1998.7111

Jiang, J. P., Jia, J., Zhang, M., and Gao, K. Q. (2018). Osteology of Batrachuperus londongensis (Urodela, Hynobiidae): study of bony anatomy of a facultatively neotenic salamander from Mount Emei, Sichuan Province, China. PeerJ 6:e4517. doi: $10.7717 /$ peerj. 4517

Kemp, N. E., and Hoyt, J. A. (1965b). Influence of thyroxine on ossification of the parasphenoid bone in the skull of Rana pipiens. Am. Zool. 5:710.

Kemp, N. E., and Hoyt, J. A. (1965a). Influence of thyroxine on order of ossification of bones of the skull of Rana pipiens. Am. Zool. 5:719.

Kemp, N. E., and Hoyt, J. A. (1969). Ossification of the femur in thyroxine-treated tadpoles of Rana pipiens. Dev. Biol. 20, 287-410.

Kerney, R., Meegaskumbura, M., Manamendra-Arachchi, K., and Hanken, J. (2007). Cranial ontogeny in Philautus silus (Anura: Ranidae: Rhacophorinae) reveals few similarities with other direct-developing anurans. J. Morphol. 268, 715-725. doi: 10.1002/jmor.10545

Kerney, R., Wassersug, R., and Hall, B. K. (2010). Skeletal advance and arrest in giant non-metamorphosing African clawed frog tadpoles (Xenopus laevis: Daudin). J. Anat. 216, 132-143. doi: 10.1111/j.1469-7580.2009.01176.x

Larras-Regard, E. (1985). "Hormonal determination of neoteny in facultative neotenic urodeles," in Metamorphosis, eds M. Balls and M. Bownes (Oxford: Clarendon Press), 294-312.

Larras-Regard, E., Taurog, A., and Dorris, M. (1981). Plasma T4 and T3 levels in Ambystoma tigrinum at various stages of metamorphosis. Gen. Comp. Endocrinol. 43, 443-450. doi: 10.1016/0016-6480(81)90228-8

Larsen, J. H. (1963). The Cranial Osteology of Neotenic and Transformed Salamanders and its Bearing on Interfamilial Relationships. Ph.D. Dissertation. Seattle, WA: University of Washington.

Larsen, J. H. (1968). Ultrastructure of thyroid follicle cells of three salamanders (Ambystoma, Amphiuma, and Necturus) exhibiting varying degrees of neoteny. J. Ultrastruct. Res. 24, 190-209. doi: 10.1016/s0022-5320(68)90058-0

Laslo, M., Denver, R. J., and Hanken, J. (2019). Evolutionary conservation of thyroid hormone receptor and deiodinase expression dynamics in ovo in a direct-developing frog, Eleutherodactylus coqui. Front. Endocrinol. 10:307. doi: $10.3389 /$ fendo.2019.00307

Laudet, V. (2011). The origins and evolution of vertebrate metamorphosis. Curr. Biol. 21, R726-R737. doi: 10.1016/j.cub.2011.07.030

Lebedkina, N. S. (1979). Evolution of Amphibian Skull. Moscow: Nauka.

Lebedkina, N. S. (1986). "Development of correlative systems in phylogeny and ontogeny," in Animal Morphology and Evolution, eds E. I. Vorobyeva and N. S. Lebedkina (Moscow: Nauka), 95-101.

Lebedkina, N. S. (2004). Evolution of Amphibian Skull (Translated and Edited by S.V. Smirnov). Sofia: Pensoft Publishers.

Lukas, P., and Olsson, L. (2020). Sequence of chondrocranial development in the oriental fire bellied toad Bombina orientalis. J. Morphol. 281, 688-701. doi: $10.1002 /$ jmor. 21138

Lynn, W. G. (1942). The Embryology of Eleutherodactylus Nubicola, an Anuran Which Has no Tadpole Stage. Washington, DC: Carnegie Institution.

Lynn, W. G. (1961). Types of amphibian metamorphosis. Am. Zool. 1, 151-161. doi: $10.1093 / \mathrm{icb} / 1.1 .151$

Lynn, W. G., and Lutz, B. (1946). The Development of Eleutherodactylus Guentheri Stdnr. 1864. Portuguese: Boletim do Museu Nacional Zoologia.

Maglia, A. M., and Púgener, L. A. (1998). Skeletal development and adult osteology of Bombina orientalis (Anura: Bombinatoridae). Herpetologica 54, 344-363.

Marks, S. B. (2000). "Skull development in two plethodontid salamanders (genus Desmognathus) with different life histories," in The Biology of Plethodontid Salamanders, eds R. C. Bruce, R. G. Jaeger, and L. D. Houck (New York, NY: Kluwer Academic Publishers), 261-276. doi: 10.1007/978-1-4615-42 55-1_12

Matsuda, R. (1987). Animal Evolution in Changing Environments with Special Reference to Abnormal Metamorphosis. New York, NY: Wiley-Interscience.

Medvedeva, I. M. (1975). The Olfactory Organ in Amphibians and its Phylogenetic Significance. Leningrad: Nauka. 
Medvedeva, I. M. (1986). "On the origin of nasolacrimal duct in Tetrapoda," in Studies in Herpetology. Third General Meeting of the Societas Europaea Herpetologica, ed. Z. Roček (Prague: Charles University), 37-40.

Mitsui, N., Fujii, T., Miyahara, M., Oka, T., Kashiwagi, A., Kashiwagi, K., et al. (2006). Development of metamorphosis assay using Silurana tropicalis for the detection of thyroid system-disrupting chemicals. Ecotoxicol. Environ. Saf. 64, 281-287. doi: 10.1016/j.ecoenv.2005.07.007

Mueller, R. L., Macey, J. R., Jaekel, M., Wake, D. B., and Boore, J. L. (2004). Morphological homoplasy, life history evolution, and historical biogeography of plethodontid salamanders inferred from complete mitochondrial genomes. Proc. Natl. Acad. Sci. USA 101, 13820-13825. doi: 10.1073/pnas.0405785101

Pugener, L. A., and Maglia, A. M. (2007). Skeletal morphology and development of the olfactory region of Spea (Anura: Scaphiopodidae). J. Anat. 211, 754-768.

Regards, E., Taurog, A., and Nakashima, T. (1978). Plasma thyroxine and triiodothyronine levels in spontaneously metamorphosing Rana catesbeiana tadpoles and in adult anuran amphibia. Endocrinology 102, 674-684. doi: 10.1210/endo-102-3-674

Reilly, S. M. (1987). Ontogeny of the hyobranchial apparatus in the salamanders Ambystoma talpoideum (Ambystomatidae) and Notophthalmus viridescens (Salamandridae): the ecological morphology of two neotenic strategies. J. Morphol. 191, 205-214. doi: 10.1002/jmor.1051910210

Reilly, S. M., and Altig, R. (1996). Cranial ontogeny in Siren intermedia (Caudata: Sirenidae): paedomorphic, metamorphic, and novel patterns of heterochrony. Copeia 1996:29. doi: 10.2307/1446939

Reilly, S. M., Wiley, E. O., and Meinhardt, D. J. (1997). An integrative approach to heterochrony: the distinction between interspecific and intraspecific phenomena. Biol. J. Linn. Soc. Lond. 60, 119-143. doi: 10.1111/j.1095-8312. 1997.tb01487.x

Reiss, J. (1996). Palatal metamorphosis in basal caecilians (Amphibia: Gymnophiona) as evidence for lissamphibian monophyly. J. Herpetol. 30, 27-39. doi: $10.2307 / 1564703$

Reiss, J. (2002). The phylogeny of amphibian metamorphosis. Zoology 105, 85-96. doi: 10.1078/0944-2006-00059

Roček, Z. (2003). "Larval development and evolutionary origin of the anuran skull," in Amphibian Biology Osteology, Vol. Vol 5, ed. H. Heatwole (Chipping Norton: Surrey Beatty \& Sons), 1875-1995.

Roček, Z., Halámková, L., and Muzzopappa, P. (2021). Developmental dynamics of two closely related species Bombina bombina and B. variegata (Amphibia: Anura) in the context of their fossil evidence. Hist. Biol. doi: 10.1080/08912963. 2020.1867979

Rose, C. S. (1999). "Hormonal control in larval development and evolutionAmphibians," in The Origin and Evolution of Larval Forms, eds B. K. Hall and M. H. Wake (Cambridge, MA: Academic Press), 167-216. doi: 10.1016/b978012730935-4/50007-9

Rose, C. S. (1995c). Skeletal morphogenesis in the urodele skull: I. Postembryonic development in the Hemidactyliini (Amphibia: Plethodontidae). J. Morphol. 223, 125-148. doi: 10.1002/jmor.1052230203

Rose, C. S. (1995a). Skeletal morphogenesis in the urodele skull: II. Effect of developmental stage in thyroid hormone-induced remodeling. J. Morphol. 223, 149-166. doi: 10.1002/jmor.1052230204

Rose, C. S. (1995b). Skeletal morphogenesis in the urodele skull: III. Effect of hormone dosage in TH-induced remodeling. J. Morphol. 223, 243-261. doi: 10.1002/jmor.1052230303

Rose, C. S. (1996). An endocrine-based model for developmental and morphogenetic diversification in metamorphic and paedomorphic urodeles. J. Zool. 239, 253-284. doi: 10.1111/j.1469-7998.1996.tb05451.x

Rose, C. S. (2003). "The developmental morphology of salamander skulls," in Amphibian Biology Osteology, Vol. Vol. 5, ed. H. Heatwole (Chipping Norton: Surrey Beatty \& Sons Ltd), 1684-1781.

Rose, C. S., and Cahill, J. W. (2019). How thyroid hormones and their inhibitors affect cartilage growth and shape in the frog Xenopus laevis. J. Anat. 234, 89-105. doi: 10.1111/joa.12897

Rose, C. S., and Reiss, J. (1993). "Metamorphosis and the vertebrate skull: ontogenetic patterns and developmental mechanisms," in The Skull Development, Vol. Vol. 1, eds J. Hanken and B. K. Hall (Chicago, IL: University of Chicago Press), 289-346.

Rosenkilde, P., and Ussing, A. P. (1996). What mechanisms control neoteny and regulate induced metamorphosis in urodeles? Int. J. Dev. Biol. 40, 665-673.
Rosenkilde, P. (1985). "The role of hormones in the regulation of amphibian metamorphosis," in Metamorphosis, eds M. Balls and M. Bownes (Oxford: Clarendon Press), 221-259.

Rot-Nikcevic, I., and Wassersug, R. J. (2004). Arrested development in Xenopus laevis tadpoles: how size constrains metamorphosis. J. Exp. Biol. 207, 21332145. doi: $10.1242 / \mathrm{jeb} .01002$

Ruibal, R., and Thomas, E. (1988). The obligate carnivorous larvae of the frog, Lepidobatrachus laevis (Leptodactylidae). Copeia 1988, 591-604. doi: 10.2307/ 1445377

Safi, R., Begue, A., Hänni, C., Stehelin, D., Tata, J. R., and Laudet, V. (1997a). Thyroid hormone receptor genes of neotenic amphibians. J. Mol. Evol. 44, 595-604. doi: 10.1007/pl00006182

Safi, R., Deprez, A., and Laudet, V. (1997b). Thyroid hormone receptors in perennibranchiate amphibians. Int. J. Dev. Biol. 41, 533-535.

Schlosser, G. (2001). Using heterochrony plots to detect the dissociated coevolution of characters. J. Exp. Zool. 291, 282-304. doi: 10.1002/jez.1104

Schoch, R. R. (1998). Homology of cranial ossifications in urodeles. Neues Jahrb. Geol. Paläontol. Monatsh. 1998, 1-25. doi: 10.1127/njgpm/1998/1998/1

Schoch, R. R. (2002). The evolution of metamorphosis in temnospondyls. Lethaia 35, 309-327. doi: 10.1080/002411602320790634

Schoch, R. R. (2009). Evolution of life cycles in early amphibians. Annu. Rev. Earth Planet Sci. 37, 135-162. doi: 10.1146/annurev.earth.031208.100113

Schoch, R. R., and Fröbisch, N. (2006). Metamorphosis and neoteny: alternative pathways in an extinct amphibian clade. Evolution 60, 1467-1475. doi: 10.1554/ 05-632.1

Senevirathne, G., Baumgart, S., Shubin, N., Hanken, J., and Shubin, N. H. (2020). Ontogeny of the anuran urostyle and the developmental context of evolutionary novelty. Proc. Natl. Acad. Sci. U.S.A. 117, 3034-3044. doi: 10.1073/pnas. 1917506117

Sheil, C. A., Jorgensen, M., Tulenko, F., and Harrington, S. (2014). Variation in timing of ossification affects inferred heterochrony of cranial bones in Lissamphibia. Evol. Dev. 16, 292-305. doi: 10.1111/ede.12092

Smirnov, S. V. (1992). The influence of variation in larval period on adult cranial diversity in Pelobates fuscus (Anura: Pelobatidae). J. Zool. 226, 601-612. doi: 10.1111/j.1469-7998.1992.tb07503.x

Smirnov, S. V. (2006). Metamorphosis in the Urodelan amphibians: patterns, regulation mechanisms, and evolution. Zh. Obshch. Biol. 67, 323-334. doi: 10.1016/j.parint.2016.03.011

Smirnov, S. V., and Vasil'eva, A. B. (2002). The bony skull of the siberian salamander Salamandrella keyserlingi (Amphibia: Urodela: Hynobiidae) and the role of thyroid hormones in its development. Dokl. Biol. Sci. 385, 387-389.

Smirnov, S. V., and Vassilieva, A. B. (2003). Skeletal and dental ontogeny in the smooth newt, Triturus vulgaris (Urodela: Salamandridae): role of thyroid hormone in its regulation. Rus. J. Herpetol. 10, 93-110.

Smirnov, S. V., and Vassilieva, A. B. (2005). Skull development in normal, TH-exposed, and goitrogen-treated axolotls, Ambystoma mexicanum. Russ. J. Herpetol. 12, 113-126. doi: 10.1016/0014-4886(76)90 239-9

Smirnov, S. V., and Vassilieva, A. B. (2009). Number of ossification centers in the anuran cranial bones depends upon the rate of development: experimental evidence. Rus. J. Herpetol. 16, 167-176.

Smirnov, S. V., and Vassilieva, A. B. (2014). Thyroid hormones in the skeletogenesis and accessory sources of endogenous hormones in Xenopus laevis (Amphibia; Anura) ontogeny: experimental evidence. Dokl. Biol. Sci. 455, 136-138. doi: $10.1134 / \mathrm{s} 0012496614020185$

Smirnov, S. V., Merkulova, K. M., and Vassilieva, A. B. (2020). Skull development in the Iberian newt, Pleurodeles waltl (Salamandridae: Caudata: Amphibia): timing, sequence, variations, and thyroid hormone mediation of bone appearance. J. Anat. 237, 543-555.

Smirnov, S. V., Vassilieva, A. B., and Merkulova, K. M. (2010). The nasal bone of the Iberian ribbed newt (Pleurodeles walt; Salamandridae, Urodela): development and regulatory mechanism of its ontogeny. Dokl. Biol. Sci. 431, 113-116. doi: $10.1134 / \mathrm{s} 0012496610020122$

Smirnov, S. V., Vassilieva, A. B., and Merkulova, K. M. (2011). Thyroid hormone mediation in skull development of Siberian newt, Salamandrella keyserlingi (Urodela: Hynobiidae), with comparison to other species. Rus. J. Herpetol. 18, 203-209. 
Tata, J. R. (1999). Amphibian metamorphosis as a model for studying the developmental actions of thyroid hormone. Biochimie 81, 359-366. doi: 10.1016/s0300-9084(99)800 82-0

Trueb, L., and Alberch, P. (1985). Miniaturization of the anuran skull: a case study of heterochrony. Fortschr. Zool. 30, 113-121.

Vassilieva, A. B. (2017). Heterochronies in the cranial development of Asian tree frogs (Amphibia: Anura: Rhacophoridae) with different life histories. Dokl. Biol. Sci. 473, 50-52. doi: 10.1134/s001249661702 $003 \mathrm{x}$

Vassilieva, A. B., and Smirnov, S. V. (2007). The role of thyroid hormones in the bony skull development in the common frog (Rana temporaria, Ranidae). Dokl. Biol. Sci. 413, 111-114. doi: 10.1134/s001249660702 0056

Vater, M. (2007). Is the prefrontal bone in Alpine newt (Triturus alpestris Laurenti, 1768) of dual origin? J. Anat. 211, 290-295. doi: 10.1111/j.1469-7580.2007. 00768.x

Vera Candioti, M. F. (2007). Anatomy of anuran tadpoles from lentic water bodies: systematic relevance and correlation with feeding habits. Zootaxa 1600, 1-175. doi: 10.11646/zootaxa.1600.1.1

Vera Candioti, M. F., Goldberg, J., Akmentins, M. S., Costa, P. N., Goulart Taucce, P. P., and Pombal, J. Jr. (2020). Skeleton in the closet: hidden diversity in patterns of cranial and postcranial ontogeny in Neotropical direct-developing frogs (Anura: Brachycephaloidea). Org. Divers. Evol. 20, 763-783. doi: 10.1007/s13127-020-004 67-8

Wake, M. H. (1989). Metamorphosis of the hyobranchial apparatus in Epicrionops (Amphibia: Gymnophiona: Rhinatrematidae): replacement of bone by cartilage. Ann. Sci. Nat. Zool. 10, 171-182.

Wake, M. H. (2003). “The osteology of caecilians," in Amphibian Biology Osteology, Vol. Vol. 5, ed. H. Heatwole (Chipping Norton: Surrey Beatty and Sons), 1809-1876.

Wassersug, R. J. (1976). A procedure for differential staining of cartilage and bone in whole formalin-fixed vertebrates. Stain Technol. 51, 131-134. doi: 10.3109/ 10520297609116684
Weisbecker, V., and Mitgutsch, C. (2010). A large-scale survey of heterochrony in anuran cranial ossification patterns. J. Zool. Syst. Evol. Res. 48, 332-347. doi: 10.1111/j.1439-0469.2010.00570.x

Weber, G. M., Farrar, E. S., Tom, C. K. F., and Grau, E. G. (1994). Changes in whole-body thyroxine and triiodothyronine concentrations and total content during early development and metamorphosis of the toad Bufo marinus. Gen. Comp. Endocrinol. 94, 62-71. doi: 10.1006/gcen.1994.1060

Weil, M. R. (1986). Changes in plasma thyroxine levels during and after spontaneous metamorphosis in a natural population of the green frog, Rana clamitans. Gen. Comp. Endocrinol. 62, 8-12. doi: 10.1016/0016-6480(86)90 088-2

Wiens, J. J. (1989). Ontogeny of the skeleton of Spea bombifrons (Anura: Pelobatidae). J. Morphol. 202, 29-51. doi: 10.1002/jmor.1052020104

Yeatman, H. C., and Miller, H. B. (1985). A naturally metamorphosed Gyrinophilus palleucus from the type-locality. J. Herpetol. 19, 304-306. doi: 10.2307/1564190

Yeh, J. (2002). The effect of miniaturized body size on skeletal morphology in frogs. Evolution 56, 628-641. doi: 10.1554/0014-3820(2002)056[0628: teombs]2.0.co;2

Conflict of Interest: The authors declare that the research was conducted in the absence of any commercial or financial relationships that could be construed as a potential conflict of interest.

Publisher's Note: All claims expressed in this article are solely those of the authors and do not necessarily represent those of their affiliated organizations, or those of the publisher, the editors and the reviewers. Any product that may be evaluated in this article, or claim that may be made by its manufacturer, is not guaranteed or endorsed by the publisher.

Copyright (C) 2021 Vassilieva and Smirnov. This is an open-access article distributed under the terms of the Creative Commons Attribution License (CC BY). The use, distribution or reproduction in other forums is permitted, provided the original author(s) and the copyright owner(s) are credited and that the original publication in this journal is cited, in accordance with accepted academic practice. No use, distribution or reproduction is permitted which does not comply with these terms. 